\title{
El abuso del veto presupuestario del gobierno a iniciativas legislativas de la oposición en el actual escenario parlamentario español ${ }^{*}$
}

\author{
Dr. David PARRA GÓMEZ \\ Universidad de Murcia
}

\begin{abstract}
Resumen: Una de las principales consecuencias de la crisis del bipartidismo que ha supuesto la radical transformación, tras las sucesivas elecciones autonómicas y generales celebradas desde 2015, de la composición de las Asambleas de las Comunidades Autónomas y de las Cortes Generales, ha sido la de acabar con las fáciles mayorías de Gobierno, lo cual está generando enfrentamientos constantes entre el Ejecutivo y el Parlamento. Precisamente, uno de estos conflictos se ha ocasionado por el abrumador uso que el Ejecutivo presidido por Mariano Rajoy hizo, en contra de lo que hasta ese momento había sido la práctica habitual, de su prerrogativa de veto presupuestario de proposiciones de ley presentadas por la oposición, y que ha situado a la misma en el primer plano del debate jurídico. Al análisis de algunas de las cuestiones más controvertidas que plantea la potestad gubernamental de veto presupuestario, como dilucidar si existe algún margen de apreciación de la Cámara correspondiente para controlar la disconformidad del Gobierno o cuáles son las posibilidades de que dispone el Gobierno para reaccionar cuando la Cámara rechaza su veto, así como de su utilización práctica tanto en el ámbito estatal como en el autonómico en un contexto parlamentario fraccionado, dedicamos el presente trabajo de investigación.
\end{abstract}

Abstract: One of the main consequences of the bipartisan crisis that has led to the radical transformation, following the successive regional and general

\footnotetext{
* Este artículo obtuvo, el pasado año académico 2018-2019, el Premio Reina María Cristina, en su séptima edición, en la modalidad de Derecho, patrocinado por el Banco Santander. El jurado calificador estuvo conformado por: D. José Iturmendi Morales (Presidente), Catedrático de Filosofia del Derecho UCM, Decano Emérito de la Facultad de Derecho de la UCM; D. Rafael Navarro-Valls, Catedrático de Derecho Eclesiástico del Estado de la UCM, Vicepresidente de la Real Academia de Jurisprudencia y Legislación; D. José Manuel Armada Vadillo, Asesor Jurídico de la Armada y General Auditor, y D. Francisco José Zamora García (Secretario), Decano de Derecho RCU Escorial-María Cristina.
} 
elections held since 2015, of the composition of the Assemblies of the Autonomous Communities and of the National Parliament has been to end the easy majorities of Government, which is generating constant confrontations between the Executive and Parliament. Precisely, one of these conflicts has been caused by the overwhelming use that the Executive chaired by Mariano Rajoy made, contrary to what until then had been the usual practice, of its budget veto prerogative of proposals of law presented by the opposition, and which has placed said institute at the forefront of the legal debate. The analysis of some of the most controversial issues raised by the governmental power of budgetary veto, such as clarifying whether there is any margin of appreciation of the corresponding Chamber to control the disagreement of the Government or what are the possibilities available to the Government to react when Chamber rejects its veto, as well as its practical use both at the state and regional level in a fractional parliamentary context, is the purpose of this research work.

Palabras clave: parlamento, gobierno, veto presupuestario.

Keywords: parliament, government, budget veto.

\section{Sumario:}

\section{Introducción.}

II. Un esbozo del actual panorama parlamentario fraccionado.

III. El profuso ejercicio del veto presupuestario del Gobierno a proposiciones de ley en unas legislaturas fragmentadas.

3.1. El abuso del veto presupuestario en la XII Legislatura de las Cortes Generales: crónica de un enfrentamiento.

3.2. La práctica del veto presupuestario en las Comunidades Autónomas.

IV. Algunas consideraciones sobre la prerrogativa de veto presupuestario y su eventual rechazo por parte de la Cámara.

4.1. ¿Qué margen de apreciación tiene la Cámara a la hora de calificar el veto presupuestario? 
4.1.1. Una primera doctrina del Tribunal Constitucional un tanto equívoca.

4.1.2. La visión restrictiva de la potestad de veto en la reciente doctrina del Alto Tribunal.

4.2. ¿De qué vías dispone el Gobierno -estatal o autonómico- para impulsar el control del acuerdo por el que Cámara rechaza su veto?

\section{Conclusiones.}

VI. Bibliografía citada. 



\section{INTRODUCCIÓN}

La radical transformación obrada por las sucesivas elecciones autonómicas y generales celebradas desde 2015 tanto en las Asambleas de las Comunidades Autónomas como en las Cortes Generales, marcada por el descenso de los dos grandes partidos mayoritarios -PP y PSOE- y la irrupción de nuevas formaciones políticas -Podemos y Ciudadanos, fundamentalmente, determinantes ahora de la gobernabilidad-, ha afectado profundamente, como no podía ser de otra forma, a la orientación de todas las funciones parlamentarias y a las relaciones Gobierno-Parlamento.

Una de las principales consecuencias de la crisis del bipartidismo fruto de la transformación parlamentaria referida ha sido la de acabar con las fáciles mayorías de Gobierno, lo cual está generando enfrentamientos constantes entre el Ejecutivo y el Parlamento. Precisamente, uno de estos conflictos se ha ocasionado por el abrumador uso que el Ejecutivo presidido por Mariano Rajoy -primero en funciones y luego en su ejercicio ordinario- ha hecho, en contra de lo que hasta ese momento había sido la práctica habitual, de su prerrogativa de oponerse por motivos presupuestarios a la tramitación de proposiciones de ley presentadas por la oposición o remitidas por las Asambleas de las Comunidades Autónomas, y que ha situado a la misma en el primer plano del debate jurídico.

$\mathrm{Al}$ análisis de las cuestiones más controvertidas que plantea la potestad gubernamental de veto presupuestario (en particular, la de dilucidar si existe algún margen de apreciación de la Cámara correspondiente para controlar los vetos manifiestamente infundados, como pudiera ocurrir si la proposición vetada no produjera realmente consecuencias en el Presupuesto o si dichas consecuencias tuvieran lugar sobre Presupuestos futuros), así como de su utilización práctica en el actual escenario político fragmentado, dedicamos la presente investigación.

\section{UN ESBOZO DEL ACTUAL PANORAMA PARLAMENTARIO FRACCIONADO}

Tras las elecciones generales de 20 de diciembre de 2015, Podemos y Ciudadanos irrumpieron en el Congreso de los Diputados como tercera y cuarta 
fuerzas parlamentarias, poniendo así fin al anterior bipartidismo imperfecto en el que Partido Popular y el Partido Socialista Obrero Español se repartían alrededor de veinte millones de votos. La composición del Congreso de los Diputados en la breve Legislatura XI fue la siguiente: G.P. popular: 119; G.P. Socialista: 89; G.P. Podemos-En Comú Podem-En Marea: 65; G.P. Ciudadanos: 40; G.P. ERC: 9; G.P. Catalán-DL: 8; G.P. EAJ-PNV: 6; y G.P. Mixto: 14.

En el Senado la fragmentación fue menor, pues el Partido Popular logró mantener -sumando los senadores designados por las Asambleas autonómicasla mayoría absoluta en esta Cámara: G.P. Popular: 142; G.P. Socialista: 67; G.P. Podemos-En Comú-Compromís-En Marea: 23; G.P. ERC: 8; G.P. CatalánDL: 8; G.P. EAJ-PNV: 7; y G.P. Mixto: 10.

La incapacidad del Congreso de los Diputados surgido de aquellas elecciones para investir a un candidato Presidente del Gobierno de España dio paso a un período de interinidad del Ejecutivo nacional de 315 días $^{1}$ en el que a éste no le fue posible, de acuerdo con lo dispuesto en el art. 21.5 b) de la Ley del Gobierno, hacer uso de su facultad de iniciativa legislativa, de modo que durante ese largo período de tiempo el procedimiento de elaboración de las leyes estatales sólo pudo ser iniciado por el resto de titulares de dicha facultad previstos en el art. 87 de la Constitución: los diputados y senadores (individualmente o como grupo), las Asambleas autonómicas y los ciudadanos (iniciativa legislativa popular).

Asimismo, en el Congreso de los Diputados asistimos a situaciones inéditas durante aquel período de interinidad, como plantones de Ministros a convocatoria de comisiones o la ausencia del Gobierno en una sesión plenaria de control. Estas situaciones provocaron que, por primera vez desde la entrada en vigor de la Constitución de 1978, la Cámara Baja y el Gobierno de la Nación se enfrentaran ante el Tribunal Constitucional a cuenta del control parlamentario que el primero puede ejercer sobre el segundo cuando éste se encuentra en funciones. Conflicto de atribuciones que ha sido resuelto recientemente (STC 124/2018, de 14 de noviembre) a favor del Congreso ${ }^{2}$.

\footnotetext{
${ }^{1}$ Computados, de acuerdo con lo dispuesto en los artículos 100 de la Constitución y 21.1 y 2 de la Ley del Gobierno, desde el cese del Gobierno tras la celebración de las elecciones generales de 20 de diciembre de 2015 (Real Decreto 1167/2015, de 21 de diciembre) hasta la toma de posesión de Mariano Rajoy como Presidente del Gobierno el 31 de octubre de 2016 (el día siguiente de su nombramiento por el Real Decreto 414/2016, de 30 de octubre). Este período de interinidad incluyó, pues, la XI Legislatura (transcurrida del 13 de enero al 3 de mayo de 2016) y casi 4 meses de la XII (cuyo inicio tuvo lugar el 19 de julio de 2016).

${ }^{2}$ En efecto, el Alto Tribunal ha subrayado en esta sentencia, aprobada por unanimidad, que la función de control es consustancial a la forma de gobierno parlamentaria y no está excluida
} 
En las elecciones generales de 26 de junio de 2016 el Partido Popular mejoró sus resultados en la Cámara Baja, aunque quedó lejos de la mayoría absoluta, mientras que Podemos y Ciudadanos sufrieron un leve descenso. La concreta composición de las Cortes Generales en la Legislatura XII todavía en curso es la que sigue: Congreso de los Diputados: G.P. Popular: 134; G.P. Socialista: 84; G.P. Podemos-En Comú Podem-En Marea: 67; G.P. Ciudadanos: 32; G.P. ERC: 9; G.P. Vasco-EAJ-PNV: 5; y G.P. Mixto: 19; Senado: G.P. Popular: 148; G.P. Socialista: 62; G.P. Unidos Podemos-En Comú Podem-En Marea: 21; G.P. ERC: 12; G.P. Vasco-EAJ-PNV: 6 y G.P. Mixto: 16.

Por lo que se refiere a las Comunidades Autónomas, a lo largo de 2015 tuvieron lugar elecciones al Parlamento de Andalucía (22 de marzo), a los Parlamentos de Aragón, Asturias, Baleares, Canarias, Cantabria, Castilla-La Mancha, Castilla y León, Extremadura, Madrid, Navarra, Murcia, La Rioja y Comunidad Valenciana (24 de mayo) y al Parlamento de Cataluña (27 de septiembre); en 2016 se celebraron comicios autonómicos en el País Vasco y Galicia ( 25 de septiembre); y el 2 de diciembre de 2018 los andaluces volvieron a las urnas ${ }^{3}$. Resulta ilustrativo del fraccionamiento parlamentario que ha seguido a todos estos comicios el siguiente dato: en 8 Comunidades Autónomas (Andalucía, Aragón, Baleares, Cantabria, Castilla La-Mancha, Extremadura, Navarra y Valencia) no gobierna la lista más votada 4 .

cuando se trata de un Gobierno en funciones, que de hecho sigue actuando, aunque sea de forma limitada. La fiscalización tendrá, por ello, una intensidad diferente, pero no puede dejarse al albur de cuál sea la voluntad del Ejecutivo.

${ }^{3}$ Un nuevo partido, Vox, ha irrumpido en el Parlamento andaluz con 12 diputados, convirtiéndose en llave de la gobernabilidad de dicha comunidad al apoyar la coalición PPCiudadanos en la Junta de Andalucía.

${ }^{4}$ La única excepción a la regla general de fraccionamiento parlamentario la encontramos en Galicia, pues un solo partido -el PP- sí logró aquí la mayoría absoluta de la Cámara. Sobre algunas de las principales cuestiones suscitadas por la composición fragmentada del Congreso (Estatuto de los Diputados, función legislativa, función presupuestaria, función de nombramiento, función internacional y política de la UE) en los dos primeros periodos de sesiones de la XII Legislatura vid., GARCÍA ESCUDERO-MÁRQUEZ, P., "Un nuevo parlamento fragmentado para los 40 años de la Constitución", Revista de Derecho Político, núm. 101, 2018, pp. 67-98. Sobre las repercusiones del escenario político surgido de los comicios autonómicos de mayo de 2015 en la organización y actividad, tanto legislativa como de control, de los Parlamentos de las Comunidades Autónomas vid., BILBAO UBILLOS, J.M., "Un nuevo ciclo político sin mayorías absolutas: los Parlamentos autonómicos recobran protagonismo tras las elecciones de 2015", Revista Jurídica de Castilla y León, núm. 42, 2017, pp. 14-37; ORTEGA SANTIAGO, C., "Actualización de los instrumentos de control del parlamento (O de cómo el control parlamentario se adapta a los tiempos y a las circunstancias)", en SEIJAS VILLADANGOS, E. (coord.), Parlamento y parlamentarismo: origen y retos, Tirant Lo Blanch, Valencia, 2018, pp. 299-314; y PARRA GÓMEZ. D., "La función legislativa en Parlamentos fragmentados", en SEIJAS VILLADANGOS, E. (coord.), Parlamento y parlamentarismo...op. cit., pp. 315343. 
Pues bien, en el contexto político descrito podemos afirmar que el desencuentro entre el Gobierno y el Parlamento, o más exactamente, entre la oposición parlamentaria al Ejecutivo y éste y su mayoría, se ha convertido, tanto en el ámbito estatal como en el autonómico, en el denominador común de la actividad legislativa. Y así lo ponen de manifiesto, principalmente, tres tendencias:

1. Los Gobiernos -el estatal y los autonómicos- encuentran serias dificultades para sacar adelante muchas de sus iniciativas legislativas, dificultades que se trasladan, obviamente, a su grupo político en la Cámara ${ }^{5}$. Estas dificultades se hacen especialmente patentes a la hora de aprobar las leyes presupuestarias, que los Ejecutivos se ven obligados ahora a pactar con la oposición, en unos casos con éxito, como ocurrió con la aprobación de los Presupuestos Generales del Estado para $2018^{6}$, y en otros con peor fortuna, como ha sucedido recientemente con las cuentas estatales para 2019 presentadas por Pedro Sánchez ${ }^{7}$.

2. Asimismo, los Ejecutivos asisten con resignación no sólo a un gran incremento numérico de las iniciativas legislativas presentadas por la oposición ${ }^{8}$, sino también al de su porcentaje de éxito. Tanto es así que, en contra de la práctica habitual propia de todos los sistemas parlamentarios, según la cual el número de proposiciones de ley que se convierte en ley es muy poco relevante si se compara con el de los proyectos de ley, la iniciativa legislativa del Gobierno y la de su grupo en la Cámara han visto reducido considerablemente su tasa de éxito, especialmente en el ámbito estatal ${ }^{9}$.

\footnotetext{
${ }^{5}$ A modo de muestra, mientras que en la X Legislatura de las Cortes Generales casi la totalidad ( 4 de 5, pues 1 fue retirada) de las proposiciones de ley presentadas en el Congreso de los Diputados por el G.P. Popular fueron tomadas en consideración y finalmente aprobadas, la única proposición presentada por el G.P. Popular en la XI Legislatura no fue ni tan siquiera tomada en consideración. Fuentes: Elaboración propia a través del buscador de la página web del Congreso de los Diputados: www.congreso.es.

${ }^{6}$ Los PGE para 2018 fueron aprobados con el apoyo de Ciudadanos, PNV, UPN, Foro, Coalición Canaria y Nueva Canarias. Como ejemplo en el ámbito autonómico podemos citar el de la Región de Murcia, donde el Gobierno popular ha podido sacar adelante los sucesivos presupuestos regionales de 2016, 2017, 2018 y 2019 gracias al apoyo de Ciudadanos.

${ }^{7}$ El proyecto de ley de PGE para 2019, aprobado por el Consejo de Ministros de 11 de enero de 2019, fue rechazado por el Congreso de los Diputados en febrero con los votos de PP, Ciudadanos e independentistas catalanes. Como caso ilustrativo en el nivel autonómico se sitúa el de Extremadura, cuyos presupuestos para 2016 fueron rechazados al aprobar el Pleno de la Asamblea (sesión de 24 de noviembre de 2015) la enmienda a la totalidad presentada por el G.P. Podemos.

${ }^{8}$ A título ilustrativo, los grupos parlamentarios de la oposición en el Congreso de los Diputados presentaron en 2015, último año de la X Legislatura, 36 proposiciones de ley, mientras que en 2016 (año que engloba la XI Legislatura y casi 6 meses de la XII, legislaturas ambas caracterizadas, como sabemos, por una acentuada fragmentación parlamentaria), impulsaron 92 proposiciones. Fuentes: Elaboración propia a través del buscador de la página web del Congreso de los Diputados: www.congreso.es.

${ }^{9}$ En efecto, en la X Legislatura de las Cortes Generales el porcentaje de éxito de los proyectos de ley fue de un 98,15\% (160 de los 163 proyectos de ley remitidos), pero en la
} 
3. Por último, esos mismos Gobiernos, abandonando la que hasta ahora era también praxis constante, han llevado a cabo un prolijo uso de su prerrogativa de veto presupuestario ${ }^{10}$, que a su vez se ve rechazada cada vez con más frecuencia por las Cámaras, elevando aquel desencuentro GobiernoParlamento a la categoría de verdadero conflicto. De esta última tendencia nos ocupamos en el siguiente epígrafe.

\section{EL PROFUSO EJERCICIO DEL VETO PRESUPUESTARIO DEL GOBIERNO A PROPOSICIONES DE LEY EN UNAS LEGISLA- TURAS FRAGMENTADAS}

\subsection{El abuso del veto presupuestario en la XII Legislatura de las Cortes Generales: crónica de un enfrentamiento}

En el ámbito estatal, la aritmética parlamentaria resultado de las últimas elecciones generales ha producido todo un giro de 180 grados en la práctica de la facultad del Gobierno de la Nación reconocida en el art. 134.6 CE ${ }^{11}$ para oponerse a la tramitación parlamentaria de aquellas proposiciones de ley que suponen un aumento de los créditos o una disminución de los ingresos presupuestarios, pues de su casi total desaparición se ha pasado a un uso frecuente de la misma.

Ciertamente, una vez pasados los primeros tiempos postconstitucionales, los sucesivos Ejecutivos habían evitado por lo general hacer uso de esa capacidad de veto fundamentalmente por su coste político, prefiriendo actuar a través de su mayoría parlamentaria para rechazar en la correspondiente

Legislatura XII -en concreto, hasta el 25 de marzo de 2019, fecha de cierre de los datos utilizados en la presente investigación- el Gobierno ha remitido al Congreso de los Diputados tan sólo 35 proyectos de ley, de los cuales sólo 11 han sido aprobados, es decir, un escaso 31,42\% (y 9 de ellos, además, con modificaciones). La variación del porcentaje de aprobación de las proposiciones de ley, sin embargo, es mínimo, pasando del $2,18 \%$ en la X Legislatura (6 de las 275 proposiciones de ley presentadas), al 2,99 \% en la actual (11 de las 367 proposiciones de ley presentadas en el Congreso). Fuentes: Elaboración propia a través del buscador de la página web del Congreso de los Diputados: www.congreso.es.

${ }^{10}$ Asimismo, los Ejecutivos han promovido, a través de sus grupos políticos, la paralización de muchas iniciativas mediante prórroga de los plazos para la presentación de enmiendas. Así lo hizo, por ejemplo, el Gobierno de Rajoy con el apoyo de Ciudadanos, lo que no impidió que en alguna ocasión Ciudadanos optara por desbloquear algunas de esas iniciativas para marcar distancias con el PP. Una de ellas fue, verbigracia, la reforma de la llamada "ley mordaza" (Ley Orgánica 4/2015, de 30 de marzo, de protección de la seguridad ciudadana). El PP contraatacó desbloqueando el trámite de otras medidas, como la derogación de la prisión permanente revisable o la reforma de la ley de secretos oficiales.

${ }^{11}$ Facultad que le viene reconocida también en los Reglamentos del Congreso (art. 126. 2 y 3) y del Senado (art. 151.1 y 3), pero no en la Ley del Gobierno. 
sesión plenaria la toma en consideración de este tipo de proposiciones. La única excepción a este comportamiento la encontramos en la IX Legislatura (2008-2011), la segunda del presidente Rodríguez Zapatero, en la que 27 proposiciones de ley formuladas por diferentes grupos parlamentarios (23 en el Congreso y 4 en el Senado) sufrieron el veto del Gobierno, lo que impidió su toma en consideración por el Pleno del Congreso de los Diputados ${ }^{12}$.

Además, en los pocos casos en los que el Gobierno de turno ejercía su facultad de veto, como la mayoría de miembros de la Mesa pertenecían al grupo parlamentario de su signo político, las proposiciones de ley que no contaban con el visto bueno de aquél se daban habitualmente por decaídas.

Sin embargo, el Gobierno de Mariano Rajoy, que en la X Legislatura -con mayoría absoluta del PP- no hizo uso de esta potestad, ha vetado durante su mandato en la XII Legislatura (hasta su dimisión el 1 de junio de $2018^{13}$ ) un total $45^{14}$ proposiciones de ley presentadas en el Congreso Diputados -10 de ellas estando en funciones- ${ }^{15}$, cifra que casi duplica los vetos que llevó a cabo el ex Presidente José Luis Rodríguez Zapatero en su último mandato ${ }^{16}$.

12 Durante ocho de las 12 legislaturas democráticas, la potestad gubernamental del veto presupuestario no fue ejercida en ninguna ocasión. En consecuencia, el veto presupuestario sólo ha aparecido en escena en cuatro legislaturas: en la I, en la que el Gobierno de UCD vetó 22 proposiciones de ley; en la II, en la que el PSOE hizo lo propio en 23 ocasiones; en la IX, en la que el Gobierno del mismo signo se opuso a 23 proposiciones de ley en el Congreso y a cuatro en el Senado y en la XII Legislatura, objeto del presente trabajo, en la que el Gobierno del PP ha batido todos los registros. Fuentes: información proporcionada por el Portal de Transparencia de la Administración General del Estado: www.transparencia.gob.es. En GARCÍA-ESCUDERO MÁRQUEZ, P., La iniciativa legislativa del Gobierno, Centro de Estudios Políticos y Constitucionales, 2000, pp. 36-37, pueden verse datos concretos sobre las proposiciones de ley no tramitadas por el veto del Gobierno hasta la VI Legislatura. Vid., también, El Gobierno de Rajoy es el que ha vetado más leyes de la oposición (24/04/2017). europapress. Recuperado de www.europapress.com; y GARCÍA MAJADO, P., Del uso al abuso del veto presupuestario (19/04/2018). Agenda Pública El País. Recuperado de: www.agendapublica. elpais.com.

${ }^{13}$ Dimisión que se produjo al aprobarse la moción de censura presentada por el Grupo Parlamentario Socialista contra el Gobierno de Rajoy (la primera aprobada desde la restauración democrática en 1978) con 180 votos a favor, 169 votos en contra y 1 abstención, dando lugar a la dimisión del Gobierno de Mariano Rajoy del Gobierno y a la investidura como nuevo Presidente del Ejecutivo del candidato propuesto en la moción, el líder socialista Pedro Sánchez.

${ }^{14}$ Fuentes: Elaboración propia, con fecha de cierre de los datos consultados 25 de marzo de 2019, a través del buscador de la página web del Congreso de los Diputados: www.congreso.es. Aclaración del autor: aaunque algunos artículos de prensa consultados aseguran que son más de 50 las proposiciones vetadas, incurren en el error de computar también los casos en los que el Gobierno ha manifestado, en el ejercicio de su facultad prevista en el artículo 126.2 del Reglamento del Congreso, su criterio en contra de la toma en consideración de iniciativas por motivos distintos de sus efectos presupuestarios.

${ }^{15}$ Por lo que se refiere a las proposiciones de ley presentadas en el Senado, el Gobierno no ha hecho uso de su facultad de veto contra ninguna de las proposiciones de ley presentadas en la Cámara Alta en la Legislatura XII (en concreto, hasta el 25 de marzo de 2019, fecha de 
En concreto, el Ejecutivo de Rajoy vetó en el período analizado 35 proposiciones de ley de Grupos Parlamentarios de la Cámara Baja y 10 proposiciones de ley remitidas por Parlamentos autonómicos en ejercicio de su facultad de iniciar leyes estatales otorgada por el art. 87.2 $\mathrm{CE}^{17}$.

\section{Proposiciones de Grupos Parlamentarios vetadas:}

- 10 proposiciones del G.P. Socialista sobre universalización de la asistencia sanitaria, paralización de la LOMCE, pobreza energética, supresión de tasas judiciales, trabajadores subcontratados, IVA cultural, modificación de la unidad de convivencia a efectos de acceso y mantenimiento de pensiones no contributivas, mejora de la pensión de viudedad, reforma de la Ley de "memoria histórica" y accesibilidad universal 18 .

cierre de la consulta de datos llevada a cabo para la elaboración del presente trabajo). Fuentes: Senado, www.senado.es.

${ }^{16}$ El Gobierno de Pedro Sánchez, sin embargo, no solo no ha hecho uso de la facultad de veto gubernamental en los casi 10 meses transcurridos desde su toma de posesión, sino que reconsideró la disconformidad del Gobierno anterior a 18 proposiciones de ley de la oposición, aceptando su tramitación. Vid., El Gobierno de Sánchez acepta tramitar en el Congreso 18 proposiciones de ley de la oposición que vetó Rajoy (15/06/2018). EcoDiario. Recuperado de www.ecodiario.eleconomista.es.

${ }^{17}$ Conviene aclarar que muchas de estas proposiciones de ley vetadas fueron ya presentadas en la anterior legislatura, la XI, pero al caducar ésta por disolución de las Cortes Generales fueron trasladadas -o presentadas de nuevo- a la siguiente legislatura.

18 Proposición de Ley sobre la universalización del derecho a la asistencia sanitaria pública; Proposición de Ley Orgánica sobre la suspensión del calendario de implantación de la Ley Orgánica 8/2013, de 9 de diciembre, para la mejora de la calidad educativa; Proposición de Ley de protección de los consumidores vulnerables y contra la pobreza energética; Proposición de Ley de supresión de tasas judiciales (esta proposición ya había sido presentada en parecidos términos en la XI Legislatura); Proposición de Ley de modificación del art. 42.1 del Estatuto de los Trabajadores para garantizar la igualdad en las condiciones laborales de los trabajadores subcontratados; Proposición de Ley por la que se modifica la Ley 37/1992, de 28 de diciembre, del Impuesto sobre el Valor Añadido, en relación con el tipo impositivo aplicable a las actividades culturales; Proposición de Ley sobre modificación de la regulación de la unidad de convivencia en determinadas situaciones, a efectos del acceso y mantenimiento en el percibo de las pensiones de la Seguridad Social en su modalidad no contributiva; Proposición de Ley de mejora de la pensión de viudedad para personas perceptoras con 65 o más años de edad y menores ingresos; Proposición de Ley para la reforma de la Ley 52/2007, de 26 de diciembre, por la que se reconocen y amplían derechos y se establecen medidas en favor de quienes padecieron persecución o violencia durante la guerra civil y la dictadura; y Proposición de Ley por la que se crea el fondo de accesibilidad universal. Salvo los vetos a dos de estas proposiciones de ley (sobre paralización de la LOMCE y trabajadores subcontratados), que han sido rechazados por la Mesa, dando lugar al conflicto de atribuciones Gobierno-Congreso de los Diputados ante el Tribunal Constitucional del que se da cuenta en el texto, el resto de vetos han sido aceptados y, en consecuencia, las proposiciones vetadas han decaído, es decir, no han sido sometidas al trámite de la toma en consideración. 
- 3 del G.P. Ciudadanos sobre autoconsumo eléctrico, tasas judiciales y mejora de la autonomía universitaria ${ }^{19}$.

- 12 del G.P. Unidos Podemos-En Comú Podem-En Marea sobre tasas judiciales, ampliación de los permisos de paternidad, cierre de centrales nucleares, negociación colectiva, asistencia jurídica gratuita, mejora de prestación por hijo menor a cargo, reforma de pensiones, edad de jubilación del personal de los guardacostas, creación de un fondo estatal para la accesibilidad universal, cartera de servicios sanitarios comunes, impuesto a la banca; e integración de centros educativos privados en la red pública de centros educativos ${ }^{20}$.

- 2 del G.P. Esquerra Republicana sobre "memoria histórica" y protección de lenguas españolas distintas del castellano ${ }^{21}$.

${ }^{19}$ Proposición de Ley de medidas urgentes de fomento del autoconsumo eléctrico (una proposición similar a ésta ya había sido presentada en la XI Legislatura); Proposición de Ley para la modificación del régimen de tasas judiciales y la exención a ciertas entidades; y Proposición de Ley de mejora de la autonomía y la rendición de cuentas de las universidades españolas. Todas han decaído al aceptar la Cámara los vetos del Gobierno.

${ }^{20}$ Proposición de Ley de modificación del régimen de tasas judiciales, establecido por la Ley 10/2012, de 20 de noviembre, y de la Ley de Enjuiciamiento Civil, con la derogación del apartado $7^{\circ}$ del art. 241.1.7 LEC añadido por Ley 37/2011, de 10 de octubre, de medidas de agilización procesal; Proposición de Ley relativa a la reforma del sistema de permisos y prestaciones para el cuidado y atención de menores por parte de sus progenitores, en casos de nacimiento, adopción, guarda con fines de adopción o acogimiento; Proposición de Ley para el cierre de las centrales nucleares; Proposición de Ley de modificación del Real Decreto Legislativo 2/2015, de 23 de octubre, por el que se aprueba el texto refundido de la Ley del Estatuto de los Trabajadores, al objeto de fortalecer la negociación colectiva en la regulación de las relaciones laborales; Proposición de Ley de reforma de la Ley 1/1996, de 10 de enero, de asistencia jurídica gratuita; Proposición de Ley de modificación del Real Decreto Legislativo 8/2015, de 30 de octubre, por el que se aprueba el texto refundido de la Ley General de la Seguridad Social, para la mejora de la prestación económica por hijo o menor a cargo; Proposición de Ley sobre reforma de las pensiones y otras medidas del orden social; Proposición de Ley sobre la edad de jubilación del personal del Servicio de Guardacostas; Proposición de Ley relativa a la creación de un Fondo Estatal para la consecución efectiva y real de la Accesibilidad Universal; Proposición de Ley reguladora de la cartera de servicios comunes del Sistema Nacional de Salud; Proposición de Ley para el establecimiento de un recargo de solidaridad a las entidades de crédito; y Proposición de Ley Orgánica de modificación de la Ley Orgánica 2/2006, de 3 de mayo, de Educación para la regulación del proceso de integración voluntario de determinados centros educativos privados en la red pública de centros educativos. Todas ellas han decaído al aceptar la Cámara los vetos del Gobierno.

${ }^{21}$ Proposición de Ley de reconocimiento de todas las víctimas de la dictadura y de Recuperación de la Memoria Histórica; y Proposición de Ley Orgánica de protección, promoción y declaración de oficialidad de las lenguas españolas distintas del castellano. Estas proposiciones han decaído al aceptar la Cámara el veto del Gobierno. 
- 5 del G.P. Mixto sobre paralización de la LOMCE, modificación del régimen de tasas judiciales, prestación económica para crianza de hijos, fomento del uso del coche eléctrico y producción eléctrica por fuentes renovables y residuos ${ }^{22}$.

- 2 presentadas conjuntamente por los Grupos Socialista, Esquerra Republicana, EAJ-PNV, Unidos Podemos-En Comú Podem-En Marea y Mixto sobre subida de pensiones y fomento del autoconsumo eléctrico ${ }^{23}$.

- Y 1 proposición presentada conjuntamente por Grupos Esquerra Republicana, Unidos Podemos-En Comú Podem-En Marea y Mixto sobre emergencia habitacional y pobreza energética ${ }^{24}$.

Proposiciones de ley de Asambleas autonómicas vetadas:

- 1 de la Asamblea Regional de Murcia sobre autoconsumo energético ${ }^{25}$.

- 1 del Parlamento Vasco sobre compensación a víctimas del amianto ${ }^{26}$.

- 2 del Parlamento de Galicia sobre titularidad de la autopista de peaje AP-9 y devolución de las participaciones preferentes ${ }^{27}$.

22 Proposición de Ley sobre la paralización del calendario de la implantación de la LOMCE (Ley Orgánica 8/2013, de 9 de diciembre, para la mejora de la calidad educativa) y para la derogación de las disposiciones adoptadas en su desarrollo; Proposición de Ley de modificación del régimen de tasas judiciales, establecido por la Ley 10/2012, de 20 de noviembre, para la exención de las entidades total o parcialmente exentas en el Impuesto de Sociedades, especialmente las entidades sin fines lucrativos, y de los sujetos pasivos que tengan la consideración de entidades de reducida dimensión de acuerdo con lo previsto en la normativa reguladora del Impuesto de Sociedades; Proposición de Ley sobre mejoras en la prestación económica de la Seguridad Social para la crianza de los hijos; Proposición de Ley de medidas de fomento de la electrificación del transporte por carretera, para fomentar la movilidad con energía eléctrica; y Proposición de Ley relativa a la definición de la rentabilidad razonable de las instalaciones de producción de energía eléctrica a partir de fuentes renovables, cogeneración y residuos. Todas estas proposiciones han decaído al aceptar la Cámara los vetos del Gobierno.

${ }^{23}$ Proposición de Ley relativa a la garantía de suficiencia de la revalorización de las pensiones para el año 2017 y de medidas urgentes de reequilibrio presupuestario de la Seguridad Social; y la Proposición de Ley de medidas para el fomento del autoconsumo eléctrico. Esta última proposición ha decaído al aceptar la Cámara el veto del Gobierno.

${ }^{24}$ Proposición de Ley de emergencia habitacional en familias vulnerables en el ámbito habitacional y de la pobreza energética. Esta proposición ha decaído al aceptar la Cámara el veto del Gobierno.

${ }^{25}$ Proposición de Ley de la Asamblea Regional de Murcia sobre generación de energía eléctrica renovable para autoconsumo.

${ }^{26}$ Proposición de Ley del Parlamento Vasco sobre la creación de un fondo de compensación a las víctimas del amianto. 
- 3 del Parlamento de las Islas Baleares sobre emprendedores, régimen especial de las Islas y protección del Mar Mediterráneo ${ }^{28}$.

- 1 de la Junta General del Principado de Asturias sobre universalización de la asistencia sanitaria ${ }^{29}$.

- 1 del Parlamento de Navarra la reforma del Régimen General de la Seguridad Social ${ }^{30}$.

- Y 1 del Parlamento de Cataluña sobre víctimas de la Guerra Civil ${ }^{31}$.

La Mesa del Congreso, dominada en la Legislatura XII por la oposición ${ }^{32}$, rechazó mediante sendos acuerdos de 18 de octubre de 2016 (con los votos en contra de los miembros del PP) los vetos planteados por el Gobierno a 2 de las proposiciones de ley presentadas por el G.P. Socialista ${ }^{33}$ : la proposición de ley orgánica para la paralización del calendario de implantación de la Ley

27 Proposición de Ley Orgánica del Parlamento de Galicia de transferencia de la titularidad y competencias de la AP-9 a la Comunidad Autónoma de Galicia; y Proposición de Ley del Parlamento de Galicia de reforma de la Ley 9/2012, de 14 de noviembre, de reestructuración y resolución de entidades de crédito, para garantizar la devolución íntegra del valor nominal de las participaciones preferentes y otros instrumentos híbridos de capital y deuda subordinada a los ahorradores y pequeños inversores sin experiencia financiera.

28 Proposición de Ley del Parlamento de las Islas Baleares de modificación de la Ley 14/2013, de 27 de septiembre, de apoyo a los emprendedores y su internacionalización; Proposición de Ley del Parlamento de las Islas Baleares de modificación de la Ley 30/1998, de 29 de julio, del régimen especial de las Illes Balears; y Proposición de Ley del Parlamento de las Islas Baleares sobre la protección del mar Mediterráneo bajo la jurisdicción española de los daños que puedan producir la exploración, la investigación y la explotación de hidrocarburos y otras substancias minerales.

${ }^{29}$ Proposición de Ley de la Junta General del Principado de Asturias de Universalización del Derecho a la Asistencia Sanitaria Pública.

${ }^{30}$ Proposición de Ley del Parlamento de Navarra para la reforma de la legislación del Régimen General de la Seguridad Social;

${ }^{31}$ Proposición de Ley del Parlamento de Cataluña modificación de la Ley 52/2007, de 26 de diciembre, por la que se reconocen y amplían derechos y se establecen medidas en favor de quienes padecieron persecución o violencia durante la Guerra Civil y la Dictadura. Todas estas proposiciones de iniciativa autonómica decayeron al aceptar la Cámara los vetos del Gobierno.

${ }^{32}$ La Mesa del Congreso de los Diputados ha estado compuesta en la Legislatura XII por tres miembros del G.P. Popular -uno de los cuales ostenta la Presidencia-, dos del G.P. Socialista, dos del G.P. Podemos-En Comú Podem-En Marea y dos del G.P. Ciudadanos.

${ }^{33}$ A pesar de que la tendencia parlamentaria de estos 40 años ha consistido en aceptar los vetos gubernamentales, el levantamiento de los mismos no es una novedad de la presente Legislatura. Por ejemplo, en la II la Mesa acordó tramitar, entre otras, las proposiciones de ley sobre Cámaras Agrarias, sobre igualdad de la mujer trabajadora en las prestaciones de la Seguridad Social, sobre pensiones vitalicias del régimen especial agrario de la Seguridad Social anterior al 20 de febrero de 1974 o sobre la gratuidad de la enseñanza constitucionalmente obligatoria a las que, justamente, el Gobierno se había opuesto por razones presupuestarias. 
Orgánica 8/2013, de 9 de diciembre, para la Mejora de la Calidad Educativa ${ }^{34}$, y la proposición de reforma del Estatuto de los Trabajadores para mejorar las condiciones de los subcontratados ${ }^{35}$, por considerar que el Ejecutivo no justificaba de forma objetiva y suficiente el aumento de créditos o disminución de ingresos alegado en sus escritos de disconformidad, admitiendo ambas, en consecuencia, al trámite de la toma en consideración ${ }^{36}$.

Ante esta decisión, el Consejo de Ministros, en su reunión de 18 de noviembre de 2016, acordó requerir de la Cámara Baja la revocación de los mencionados acuerdos, alegando que éstos "violentan su competencia exclusiva de iniciativa legislativa presupuestaria y de defensa de la ejecución de los presupuestos en vigor y suponen una asunción contraria a Derecho de la competencia que al Ejecutivo corresponde de conformidad con la Constitución y el Reglamento de la Cámara", requerimientos que la Mesa rechazó (con el voto a favor de PSOE y Podemos, la abstención de Ciudadanos y el voto en contra del PP) mediante sendos escritos fechados el 20 de diciembre. Ello motivó que el Consejo de

${ }^{34}$ El oficio de disconformidad, remitido el 14 de octubre, se acompañó de un informe en el que el Ministerio de Educación, Cultura y Deporte cuantificaba en unos seiscientos millones de euros la pérdida de ingresos procedentes de fondos comunitarios derivada de la aprobación de la mencionada proposición de ley orgánica.

${ }^{35}$ El oficio de disconformidad, también remitido por oficio de 14 de octubre, iba acompañado de un informe en el que el Ministerio de Hacienda cuantificaba en unos 60 millones de euros el aumento de gastos en las empresas del sector público estatal en el presupuesto en vigor como consecuencia del incremento del gasto total en sueldos y salarios que causaría la aprobación de la mencionada proposición de ley.

${ }^{36}$ Ambas proposiciones de ley fueron tomadas en consideración, respectivamente, en las sesiones plenarias de 15 de noviembre y 20 de diciembre de 2016. La Mesa encomendó (Acuerdo de 22 de noviembre de 2016) Dictamen sobre la primera de esas proposiciones a la Comisión de Educación y Deporte (además de la apertura de un plazo de enmiendas que expiró el 15 de diciembre de 2016), y la aprobación con competencia legislativa plena de la segunda (Acuerdo de 27 de diciembre de 2016) a la Comisión de Empleo y Seguridad Social (así como la apertura de un plazo de enmiendas que expira el 17 de febrero de 2017). La toma en consideración de la proposición de ley socialista para la paralización de la LOMCE dejó claro al Gobierno que estaba solo en defensa de esta ley, lo que obligó a los populares a pactar con las CC. AA. el Real Decreto-ley 5/2016, de 9 de diciembre, de medidas urgentes para la ampliación del calendario de implantación de la LOMCE (convalidado en sesión plenaria de 21 de diciembre de 2016), y con el PSOE y Ciudadanos el texto de la propuesta para la creación de la Subcomisión del "Gran Pacto de Estado Social y Político por la Educación". A pesar de que el Decreto-ley citado hirió de muerte las reválidas y recuperó la selectividad, además de incluir otras dos concesiones al PSOE (que los alumnos de FP básica puedan obtener el título de ESO desde este curso sin tener que superar la reválida y que el itinerario que se haya elegido en la ESO no condicione los estudios posteriores, de maneara que todos los titulados puedan elegir si quieren ampliar la fase de estudios postobligatoria con el Bachillerato o los ciclos de FP), los socialistas parecen no tener intención de retirar su proposición de ley para así mantener la presión sobre el PP en busca de nuevas rectificaciones en política educativa. Vid., El PSOE mantendrá activado un plan B para derogar la Lomce (09/01/2017). La Rioja.com. Recuperado de www.larioja.com. 
Ministros, en su reunión de 13 de enero de 2017, acordara el planteamiento de sendos conflictos de atribuciones ante el Tribunal Constitucional ${ }^{37}$, resueltos recientemente por el Alto Tribunal a favor del Congreso en las SSTC 34/2018, de 12 de abril y 44/2018, de 26 de abril, respectivamente, a las que tendremos ocasión de referirnos más adelante.

En los demás casos, la Mesa decidió por lo general aceptar la disconformidad manifestada por el Ejecutivo y poner fin a la tramitación parlamentaria de las proposiciones vetadas ${ }^{38}$, si bien dejó en suspenso la tramitación de algunas de esas proposiciones a la espera, bien de un informe encargado a los Letrados de la Cámara sobre los 14 vetos formulados hasta ese momento, informe que otorgaba capacidad a la Mesa para rechazar los vetos del Gobierno por razones presupuestarias sólo cuando el Ejecutivo hubiera actuado de manera arbitraria, irresponsable o no suficientemente justificada ${ }^{39}$, bien de la respuesta del Gobierno a una solicitud de mayor aclaración y justificación del impacto presupuestario que tendrían tales iniciativas si llegaran a aprobarse, como pasó con las proposiciones sobre subida de pensiones, universalización del derecho a la asistencia sanitaria pública, supresión de tasas judiciales y pobreza energética ${ }^{40}$.

${ }^{37}$ Vid., Conflictos de atribuciones ante el Tribunal Constitucional sobre la admisión a trámite por la Mesa del Congreso de dos proposiciones de ley sobre las que el Gobierno había expresado su disconformidad (13/01/2017). Gobierno de España. Recuperado de www.lamoncloa.gob.es.

${ }^{38}$ Este fue el caso, por ejemplo, de las proposiciones de ley sobre ampliación de los permisos de paternidad y eliminación del llamado "impuesto al sol", otra vez gracias a al voto de los representantes de PP y Ciudadanos en la Mesa. Y ello a pesar de que, en relación con la proposición sobre autoconsumo eléctrico, Ciudadanos había manifestado en su día su apoyo a la misma. Vid., La oposición se une para reclamar que se elimine el 'impuesto al sol' (25/01/2017). El País. Recuperado de www.elpais.com. Así pues, la Mesa dio por buenos los motivos alegados por el Gobierno para justificar su veto a sendas proposiciones: en relación con la proposición sobre el permiso de paternidad, que su aplicación supondría un sobrecoste presupuestario de más de 3.637,83 millones de euros; y respecto a la proposición de ley contra el "impuesto al sol", que la regulación del autoconsumo energético supondría una merma en la recaudación de 162 millones de euros en impuestos y un gasto de 10 millones adicionales para compensar el déficit que provocaría la consecuente reducción de los peajes. Vid., Ciudadanos se une al PP para mantener el 'impuesto al sol' (14/03/2017). infoLibre. Recuperado de www.infolibre.es.

${ }^{39}$ Aunque finalmente asumió la tesis del Ejecutivo y acordó -con fecha de 13 de diciembre de 2016- no admitirlas al trámite de toma en consideración. Vid., Los letrados del Congreso defienden el veto del Gobierno a leyes si no es «arbitrario» (13/12/2016). ABC. Recuperado dewww.abc.es.

${ }^{40}$ En el primer caso, la proposición para la subida de las pensiones, gracias, de nuevo, a la unión de fuerzas de PP y Ciudadanos en la Mesa. Este veto fue justificado por el Ejecutivo alegando que su aplicación supondría un coste de más de 1.150 millones de euros que tendría que asumir el Estado. Vid., Congreso y Gobierno, más cerca de su segundo conflicto de atribuciones ante el TC. (13/12/2016). ABC. Recuperado de www.abc.es. En el resto de casos (asistencia sanitaria, tasas judiciales y pobreza energética), la Mesa decidió por acuerdo de todos los grupos representados en la misma. 


\subsection{La práctica del veto gubernamental en las Comunidades Autónomas}

Por lo que se refiere al ámbito autonómico, el panorama en las legislaturas iniciadas en 2015 es, sin embargo, algo más dispar ${ }^{41}$.

En la mayoría de las Comunidades Autónomas no ha surgido el conflicto Gobierno-Parlamento que nos ocupa:

- En algunos casos, como Galicia y País Vasco, porque no se han presentado por el momento proposiciones de ley financieras.

- En otros, porque el Ejecutivo autonómico, continuando con la práctica habitual a la que antes hacíamos referencia, no ha vetado ninguna de las proposiciones de este tipo presentadas por la oposición, sino que ha preferido apoyar con su grupo en la Cámara el rechazo a su toma en consideración ${ }^{42}$. Así ha ocurrido en Aragón, Baleares, Canarias, La Rioja, Navarra y Comunidad Valenciana.

- Y no faltan tampoco Comunidades Autónomas cuyas Asambleas han aceptado sin discusión los vetos formulados por los respectivos Gobiernos. Son los casos de Cataluña ${ }^{43}$, Castilla La-Mancha ${ }^{44}$ y Extremadura ${ }^{45}$.

${ }^{41}$ Consulta de datos cerrada el 25 de marzo de 2019. Fuentes: Elaboración propia a partir de los buscadores de los Parlamentos autonómicos: Parlamento de Andalucía, www.parlamentodeandalucia.es; Cortes de Aragón, www.cortesaragon.es; Junta General de Principado de Asturias.; www.jgpa.es; Parlamento de las Islas Baleares, www.parlamentib.es; Parlamento de Canarias: www.parcan.es; Parlamento de Cantabria: www.parlamento-cantabria.es; Parlamento de Cataluña: www.parlament.cat; Cortes de Castilla-La Mancha: www.cortesclm.es; Cortes de Castilla y León: www.ccyl.es; Asamblea de Extremadura: www.asambleaex.es; Parlamento de Galicia: www.parlamentodegalicia.com; Parlamento de La Rioja: www.parlamento-larioja.org; Asamblea de Madrid: www.asambleamadrid.es; Asamblea Regional de Murcia: www.asambleamurcia.es; Parlamento de Navarra: www.parlamentonavarra.es; Parlamento del País Vasco: www.legebiltzarra.eus; y Cortes Valencianas: www.corts valencianes.es.

${ }^{42}$ Después de haber expresado previamente, en muchos casos, su criterio desfavorable a dicha toma en consideración.

${ }^{43}$ El Parlamento de Cataluña ha aceptado el veto formulado por el Gobierno catalán a 1a proposición de ley presentada por el G.P. Ciudadanos de medidas urgentes para incentivar el alquiler de viviendas sociales y asequibles.

${ }^{44}$ Por ejemplo, las Cortes de Castilla-La Mancha han aceptado los vetos del Gobierno manchego a la proposición de ley de los G.P. Socialista y Podemos de Ley de medidas para la garantía y continuidad en Castilla-La Mancha de los servicios públicos como consecuencia de la entrada en vigor de la Ley 27/2013, de 27 de diciembre, de racionalización y sostenibilidad de la Administración Local.

45 Por ejemplo, la Asamblea de Extremadura ha aceptado los vetos del Gobierno extremeño a 3 "propuestas de ley" del G.P. Podemos: Propuesta de modificación de la Ley 9/2014, de 1 de octubre, por la que se regula la Renta Básica Extremeña de Inserción para paliar y reducir la pobreza energética en Extremadura; Propuesta de Ley de Medidas Urgentes para afrontar la Emergencia 
Por el contrario, seis Parlamentos autonómicos sí han desoído el veto del Gobierno a iniciativas financieras de la oposición:

- El Parlamento de Andalucía rechazó en la X Legislatura (marzo de 2015-diciembre 2018) 2 vetos de la Junta a proposiciones de ley del G.P. Podemos (sobre cuentas abiertas y pobreza energética) ${ }^{46}$, por entender que tales iniciativas no implicaban el aumento de créditos presupuestarios alegado $^{47}$.

- La Junta General del Principado de Asturias ha ignorado el veto del Gobierno asturiano a 1 proposición de ley del G.P. Podemos (sobre liquidación de deudas) $)^{48}$, por considerarla "manifiestamente infundada", acuerdo que, además, ha sido confirmado por el Pleno.

\section{- La Asamblea Regional de Murcia ha rechazado 8 de los $10^{49}$ vetos formulados por el Consejo de Gobierno. En concreto, los vetos a 4}

Habitacional en Extremadura; y Propuesta de Ley para paliar y reducir la pobreza energética en Extremadura.

${ }^{46}$ Proposición de Ley de Cuentas Claras y Abiertas para la Administración Pública Andaluza; y Proposición de Ley para paliar y reducir la pobreza energética en Andalucía. Sin embargo, el veto formulado por el Gobierno andaluz a una proposición del G.P. Izquierda Unida Los Verdes (Proposición de Ley de la Cámara de Cuentas de Andalucía) sí ha sido aceptado por la Mesa.

${ }^{47}$ A 25 de marzo de 2019, fecha de cierre de los datos consultados para el presente trabajo, en la actual legislatura andaluza iniciada tras las elecciones de 2 de diciembre de 2018, la XI, sólo se han presentado 2 proposiciones de ley (1 de G.P. Socialista y 1 de G.P. Adelante Andalucía), y sólo la primera ha sido remitida al Consejo de Gobierno andaluz a fin de que muestre su criterio respecto a la toma en consideración, así como conformidad o no a la tramitación si implicara aumento de los créditos o disminución de los ingresos presupuestarios, sin que por el momento se haya evacuado dicho trámite.

${ }^{48}$ Proposición de Ley de suspensión de liquidaciones de las deudas reclamadas a herederos de los usuarios fallecidos de los servicios residenciales públicos del organismo autónomo Establecimientos Residenciales para Ancianos de Asturias. Si bien, por otra parte, la Mesa sí ha aceptado cuatro vetos o "disconformidades presupuestarias" manifestadas por el Consejo de Gobierno: contra tres proposiciones de ley del G.P. Popular (Proposición de Ley de supresión del impuesto sobre hidrocarburos; Proposición de Ley de modificación del impuesto sobre sucesiones y donaciones en la Comunidad Autónoma del Principado de Asturias; y Proposición de Ley por la que se establecen medidas urgentes para reparar los daños causados y las pérdidas producidas en distintos municipios del Principado de Asturias por los incendios acontecidos durante el mes de diciembre de 2015 y enero de 2016) y una del G.P. Foro Asturias (Proposición de Ley de modificación del Texto Refundido de las disposiciones legales del Principado de Asturias en materia de tributos cedidos por el Estado, aprobado por Decreto Legislativo 2/2014, de 22 de octubre).

${ }^{49}$ La Mesa de la Cámara murciana sí ha aceptado, sin embargo, los vetos gubernamentales a 1 proposición del G.P. Socialista (Proposición de Ley para el funcionamiento pleno del Hospital Santa María del Rosell como hospital general) y a 1 del G.P. Ciudadanos (Proposición de Ley sobre modificación del Decreto Legislativo 1/2010, de 5 de noviembre, por el que se aprueba el Texto Refundido de las disposiciones legales vigentes en la Región en materia de tributos cedidos). 
proposiciones del G.P. Socialista (sobre medidas fiscales, igualdad del colectivo LGTB, parejas de hecho y gratuidad de $\operatorname{libros}^{50}$ ), 1 proposición del G.P. Podemos (sobre atención temprana ${ }^{51}$ ), 2 proposiciones presentadas conjuntamente por los Grupos Parlamentarios Socialista y Podemos (sobre televisión regional y cambio climático ${ }^{52}$ ) y 1 del G.P. Ciudadanos sobre patrimonio cultural ${ }^{53}$.

- El Parlamento de Cantabria ha ignorado el veto gubernamental a 1 proposición de ley del G.P. Popular (sobre urbanismo y vivienda protegida) ${ }^{54}$.

- La Asamblea de Madrid ha rechazado sistemáticamente todos los vetos del Gobierno regional a proposiciones de ley de la oposición (3 del G.P. Socialista sobre transparencia, cambio climático y salud bucodental ${ }^{55}, 1$ del G.P. Ciudadanos sobre policía local ${ }^{56}, 1$ presentada conjuntamente por los G.P. Socialista, Ciudadanos y Podemos relativa al Consejo de la Juventud ${ }^{57}$ y 1 del G.P. Podemos sobre modificación presupuestaria ${ }^{58}$ ), así como las 5 solicitudes de reconsideración presentadas por el Ejecutivo,

${ }^{50}$ Proposición de Ley de modificación de la Ley 7/2011, de 28 de diciembre, de medidas fiscales y de fomento económico en la Región de Murcia; Proposición de ley de igualdad social de lesbianas, gais, bisexuales, transexuales, transgénero e intersexuales y de políticas públicas contra la discriminación por orientación sexual e identidad de género en la Comunidad Autónoma de la Región de Murcia; Proposición de Ley de parejas de hecho de la Comunidad Autónoma de la Región de Murcia; y Proposición de Ley sobre gratuidad de libros de texto y material curricular en la Región.

${ }^{51}$ Proposición de Ley por la que se regula la atención temprana en la Región de Murcia.

${ }^{52}$ Proposición de Ley sobre modificación de la Ley 9/2004, de 29 de diciembre, de creación de la empresa pública regional Radiotelevisión de la Región de Murcia; Proposición de ley sobre cambio climático de la Comunidad Autónoma de la Región de Murcia.

${ }^{53}$ Proposición de Ley sobre modificación de ley 4/2007, de 16 de marzo, de patrimonio cultural de la Comunidad Autónoma de la Región.

${ }^{54}$ Proposición de Ley de modificación de la Ley de Cantabria 2/2001, de 25 de junio, de ordenación territorial y régimen urbanístico del suelo de Cantabria y de la Ley de Cantabria $5 / 2014$, de 26 de diciembre, de vivienda protegida de Cantabria, para la regulación del derecho de realojo. El Gobierno cántabro ha vetado también una proposición de ley del G.P. Podemos (Proposición de Ley para paliar y reducir la pobreza energética (electricidad, agua y gas), pero ésta ha sido finalmente retirada.

${ }^{55}$ Proposición de Ley 2/2016 de transparencia, de acceso a la información pública y de participación de la Comunidad de Madrid; Proposición de Ley 12/2016 de cambio climático de la Comunidad de Madrid; y Proposición de Ley 11/2016 de atención a la salud bucodental y de creación del Programa de Atención Dental Infantil-Comunidad de Madrid.

${ }^{56}$ Proposición de Ley 3/2016 de modificación de la Ley 4/1992, de 8 de julio, de Coordinación de Policías Locales de la Comunidad de Madrid.

${ }^{57}$ Proposición de Ley 7/2016 de creación del Consejo de la Juventud de la Comunidad de Madrid.

58 Proposición de Ley 4/2016 de modificación de la Ley 4/2012, de 4 de julio, de modificación de la Ley de Presupuestos Generales de la Comunidad de Madrid para el año 2012 y medidas urgentes de racionalización del gasto público e impulso y agilización de la actividad económica. 
alegando, fundamentalmente, que el incremento de gasto que se afirma por el Gobierno no afecta al ejercicio económico en curso $^{59}$.

- Y las Cortes de Castilla y León, en fin, han levantado el veto formulado por la Junta contra una proposición de ley presentada por el G.P. Podemos (sobre cuentas abiertas para la Administración pública de la Comunidad Autónoma ${ }^{60}$ ), al entender que ésta no tiene incidencia ni en los ingresos ni en los gastos del presupuesto en curso.

\section{ALGUNAS CONSIDERACIONES SOBRE LA POTESTAD DE VETO PRESUPUESTARIO Y SU EVENTUAL RECHAZO POR PARTE DE LA CÁMARA}

El protagonismo del Gobierno en la cuestión presupuestaria es una realidad innegable: a él le corresponde, en exclusiva, la presentación de los Presupuestos Generales del Estado (art.134.1 CE) y, tras la aprobación de éstos por las Cortes Generales, el Ejecutivo retiene importantes facultades en relación con los mismos, ya que puede presentar proyectos de ley o vetar proposiciones de ley y enmiendas que impliquen, en ambos casos, un aumento de los gastos o disminución de los ingresos presupuestarios (art. 134.5 y 6 CE).

Con el reconocimiento de la potestad del Gobierno para oponerse a la tramitación de las proposiciones de ley o enmiendas que supongan aumento de los créditos o disminución de los ingresos presupuestarios se pretende evitar que la actividad legislativa de las Cámaras deje sin virtualidad la política económica gubernamental, a la que ya habrían dado su beneplácito aprobando los Presupuestos ${ }^{61}$, salvaguardando, así, una función de gobierno que se canaliza

${ }^{59}$ La Mesa ha justificado en algún caso el rechazo del veto y de la reconsideración solicitada por el Gobierno con el argumento de que "no se está en ese momento procediendo a la aprobación de un texto legislativo, sino ante la apertura de la posibilidad de tramitación en sede parlamentaria de un texto legislativo, pudiendo subsanarse durante el procedimiento parlamentario las cuestiones expuestas en el informe remitido por el Gobierno".

${ }^{60}$ Proposición de Ley de cuentas abiertas para la Administración Pública de Castilla y León. Finalmente, esta proposición no fue tomada en consideración.

${ }^{61}$ Algo parecido a lo que ocurre en Derecho comparado, por ejemplo, en Francia, donde el art. 40 de la Constitución establece la inadmisibilidad (mediante la llamada excepción de irrecevabilité, es decir, sin necesidad siquiera de que el Gobierno lo invoque) de aquellas proposiciones de ley que den lugar a mayores gastos o menores ingresos. Sin embargo, el modelo más similar al nuestro es el alemán, ya que su norma fundamental también requiere el consentimiento gubernamental respecto de aquellas leyes que generen nuevos gastos, los eleven, o los comprometan para el futuro, así como para aquellas que supongan una reducción de los ingresos o los comprometan para el futuro. En esos casos el Gobierno Federal podrá exigir que el Parlamento aplace la aprobación de estas leyes, para lo que cuenta con un plazo 
sobre todo en la política presupuestaria dado que, como ha puesto de relieve el Tribunal Constitucional, ésta constituye "el vehículo de dirección y orientación de la política económica".

Adelantábamos en la introducción que la abrumadora cifra de vetos interpuestos por el Gobierno central en la XII Legislatura de las Cortes ha elevado a esta prerrogativa gubernamental, que constituye en sí misma un límite a la función legislativa de las Cortes, a la iniciativa legislativa no gubernamental, al derecho fundamental de participación ciudadana y al ius in officium de los parlamentarios, al primer plano de la actualidad jurídica. Pero como desde los primeros tiempos postconstitucionales tal prerrogativa ha sido objeto de amplio tratamiento doctrinal ${ }^{62}$, nos limitaremos aquí a

de seis semanas para hacer llegar un informe a las Cámaras. Vid., GIMÉNEZ SÁNCHEZ, I.M., El veto presupuestario del gobierno: ¿mecanismo de bloqueo parlamentario? (26/10/2018). Agenda Pública El País. Recuperado de: www.agendapublica.elpais.com.

${ }^{62} \mathrm{Vid}$., entre otros, PÉREZ JIMÉNEZ, P.J., "Las limitaciones a la iniciativa legislativa financiera en la Constitución española", en Revista de Derecho Político, núm. 9, 1981, pp. 111-159; AJA FERNÁNDEZ, E., "Caracteres y principios generales del procedimiento legislativo", en Anuari de Dret politic, 1983, pp. 159-171; PUNSET BLANCO, R., "La fase central del procedimiento legislativo", en Revista Española de Derecho Constitucional, núm. 14, 1985, pp. 11-134; ARCE JANÁRIZ, A., "Calificación y admisión a trámite en los procedimientos parlamentarios", en Revista Española de Derecho Constitucional, núm. 29, 1990, pp. 9-116; MARTÍNEZ LAGO, M.A., Los límites a la iniciativa de las Cortes Generales en materia presupuestaria, Ministerio de Economía y Hacienda. Centro de Publicaciones, 1990; MERINO MERCHÁN, J.F., "Las facultades de calificación de las enmiendas por las Mesas de las Cámaras", en Revista de las Cortes Generales, núm. 23, 1991, pp. 133-152; ARCE JANÁRIZ, A., "El trámite de admisión de los procedimientos parlamentarios en la Jurisprudencia Constitucional", en Revista Española de Derecho Constitucional, núm. 46, 1996, pp. 207-239; PEÑA RODRÍGUEZ, L., "Calificación y admisión a trámite de iniciativas legislativas", en $V$ Jornadas de Derecho Parlamentario, El procedimiento legislativo, 1998, pp. 351-382; GARCÍA MORILLO, J., y PÉREZ TREMPS, P., "Legislativo vs. Ejecutivo autonómicos: El problema del control del "veto presupuestario", en Parlamento y Constitución: Anuario de Derecho Parlamentario de Castilla-La Mancha, núm. 2, 1998, pp. 9-44; MERINO MERCHÁN, J.F., "Elementos para un estudio de los actos del procedimiento legislativo", en Los actos del Parlamento, Parlamento Vasco, 1999, pp. 47-135; GARCÍA ESCUDERO MÁRQUEZ, P., La iniciativa legislativa del Gobierno, Centro de Estudios Políticos y Constitucionales, 2000; VISEDO MAJÓN, F.J. y SORIANO HERNÁNDEZ, E., Las enmiendas en el procedimiento legislativo, Asociación Española de Letrados de Parlamentos, 2000; GARCÍA ESCUDERO MÁRQUEZ, P., El procedimiento legislativo ordinario en las Cortes Generales, Centro de Estudios Políticos y Constitucionales, 2006; PULIDO QUECEDEO, M., "Sobre cuestiones presupuestarias de índole parlamentaria", en Repertorio Aranzadi del Tribunal Constitucional, núm. 13, 2006, pp. 9-12; GARCÍA-ESCUDERO MÁRQUEZ, P., "Sobre la calificación de las Enmiendas de contenido presupuestario (A propósito de la STC 223/2006, de 6 de junio)", en Repertorio Aranzadi del Tribunal Constitucional, núm. 13, 2006, pp. 45-55; MARRERO GARCÍA-ROJO, A., "El control del ejercicio por el Gobierno de la facultad de veto presupuestario (Comentario a la STC 223/2006, con consideración de la STC 242/2006)", en Revista Española de Derecho Constitucional, núm. 80, 2007, pp. 309-359; SANZ PÉREZ, A.L., “Existe doble confianza en nuestro parlamentarismo? Comentario a la STC 242/2006”, 
tratar dos de las cuestiones que, sin duda, despiertan mayor interés, y más aún, si cabe, a raíz de la reciente doctrina del Tribunal Constitucional que ha venido a aclarar la primera de ellas: (i) si puede la Cámara controlar los vetos gubernamentales manifiestamente infundados, o lo que es lo mismo, cuál es el verdadero alcance del veto presupuestario del Gobierno; (ii) y de qué vías dispone el Gobierno para activar el control del acuerdo por el que Cámara, en su caso, rechaza su veto.

\section{1. ¿Qué margen de apreciación tiene la Cámara a la hora de calificar el veto gubernamental?}

Como señala Aranda Álvarez ${ }^{63}$, en los escritos que se someten a la calificación y admisión de la Mesa de la Cámara se deduce una pretensión de sus autores para que se ponga en marcha un procedimiento parlamentario o para que se incorpore alguna pretensión en alguna de sus fases. Pretensiones ambas que, precisamente, concurren en el caso que aquí nos ocupa: con la presentación de una proposición de ley sus autores pretenden que se inicie el procedimiento reglamentariamente previsto para su discusión y aprobación, mientras que con el escrito de disconformidad con la tramitación de la proposición por motivos presupuestarios lo que pretende el Gobierno es que se ponga fin a su existencia parlamentaria antes incluso de que dicha iniciativa sea debatida en el trámite de toma en consideración.

Por lo que se respecta a la calificación de ese último escrito, cabe preguntarse hasta qué punto puede la Mesa de la Cámara ${ }^{64}$ ir más allá de la verificación estricta de los requisitos formales del mismo y valorar también su contenido material y justificación. $\mathrm{O}$, dicho de otra manera, cuál es el alcance de la potestad de veto presupuestario prevista en el art. 134.5 CE. Cuestión ésta sobre la que el Tribunal Constitucional ha ido modificando su criterio en sucesivas sentencias.

en Repertorio Aranzadi del Tribunal Constitucional, núm. 3, 2007, pp. 13-37; GIMÉNEZ SÁNCHEZ, I. M., Las competencias presupuestarias del Parlamento, Centro de Estudios Políticos y Constitucionales, 2008; GARCÍA-ESCUDERO MÁRQUEZ, P., "Gobierno en funciones y función legislativa", en Cuadernos Manuel Giménez Abad, núm. 11, 2016, pp. 101-116; GIMÉNEZ SÁNCHEZ, I.M., "El control parlamentario sobre el llamado "veto presupuestario" del Gobierno", en Revista Jurídica de Castilla y León, núm. 42, 2017, pp. 76-101.

63 ARANDA ÁlVAREZ, E., Los actos parlamentarios no normativos y su control jurisdiccional, Centro de Estudios Políticos y Constitucionales, 1998, p. 164.

${ }^{64}$ La calificación del escrito de disconformidad del Gobierno corresponde a la Mesa en todas las Cámaras salvo en los Parlamentos de Navarra y Aragón, cuyos Reglamentos atribuyen tal función, respectivamente, a la Junta de Portavoces (148.3 RPN) y a la Comisión de Economía y Presupuestos (139.3 RCA). 


\subsubsection{Una primera doctrina del Tribunal Constitucional un tanto equívoca}

El TC se pronunció por primera vez sobre el alcance de la potestad de veto del Gobierno en la STC 223/2006, de 6 de julio, que resolvió un recurso de inconstitucionalidad interpuesto por el Gobierno de la Junta de Extremadura y 81 diputados del G.P. Socialista contra el Reglamento de la Asamblea de Extremadura, en la redacción dada por la reforma de 29 de mayo de 1997. Esta reforma afectaba a la tramitación de las proposiciones de ley y enmiendas con alcance presupuestario del año en curso, con el objeto de prevenir eventuales abusos por parte del Gobierno al obstaculizar la tramitación de aquellas iniciativas que supusiesen aumento o disminución del techo de gasto público previamente autorizado por la Asamblea extremeña. La solución ofrecida por el Reglamento consistía en atribuir a la Mesa el papel de filtro previo ante discrepancias con las decisiones del Gobierno, cuya decisión última se ponía en manos del Pleno de la Cámara.

La sentencia declaró esta normativa inconstitucional (en concreto, los arts. 111.1 párrafo segundo 2 y 121.4 párrafo segundo) por entender que era contraria a la regla prevista en la Constitución (art. 134.6 CE) y -en parecidos términos- en el Estatuto de Autonomía extremeño (entonces en el art. 60 b), y en la actualidad en el art. 23.1) ${ }^{65}$, señalando que "Mesa y Pleno se erigen en jueces de si concurren o no las circunstancias que permiten al Consejo de Gobierno de la Junta de Extremadura oponerse a la tramitación de iniciativas normativas que alteren el equilibrio presupuestario. Esto, sencillamente, supone modificar la regla prevista en el EAEx, que en su artículo 60 b) establece que corresponde al Consejo de Gobierno de la Junta de Extremadura la conformidad para tramitar toda proposición o enmienda que suponga aumento de los créditos o disminución de los ingresos presupuestarios, sin prever los límites a dicha potestad que se derivan de las normas recurridas".

A juicio del Alto Tribunal, tales normas, por tanto, "alteran el sistema de relaciones entre la Junta y la Asamblea previsto estatutariamente, sistema de relaciones que, respecto al necesario respeto a los compromisos económicos asumidos mediante la aprobación por dicha Asamblea del presupuesto de la

${ }^{65}$ Regla que, como remarca el Tribunal Constitucional en la sentencia, responde al equilibrio de poderes propio del parlamentarismo racionalizado. A este respecto, Aragón Reyes afirma que "este veto gubernamental configura una característica muy relevante del parlamentarismo "racionalizado", mediante la cual se garantiza que, una vez aprobado el Presupuesto por la Cámara, la dirección y ejecución del mismo queda en manos del Gobierno, sin que el Parlamento pueda, sin la aquiescencia del Gobierno, modificarlo o desfigurarlo a lo largo de su vigencia anual" ("La organización institucional de las Comunidades Autónomas", en Revista Española de Derecho Constitucional, núm. 79, 2007, p. 24). 
Comunidad Autónoma, elaborado y ejecutado por el Consejo de Gobierno de la Junta, y examinado, enmendado, aprobado y controlado por la Asamblea [art. 60 a) EAEx], es claro en el sentido de que solamente se podrán alterar dichos compromisos con el consentimiento del Ejecutivo autonómico" (FJ 6). Así pues, la STC 223/2006 viene a defender el carácter "políticamente libre" del Gobierno en el ejercicio de su facultad de veto por motivos presupuestarios.

No fueron pocas las críticas vertidas sobre este pronunciamiento, fundamentalmente porque, en palabras de García-Escudero Márquez, "fundar una potestad de ejecución del Gobierno tan extensa en materia presupuestaria, lejos de ser real, contribuye a una minusvaloración de las potestades parlamentarias y a un desequilibrio de las relaciones gobierno-parlamento, que no pueden obviarse sobre la tesis de la doble confianza que maneja la Sentencia" ${ }^{\prime \prime 6} ; 0$, como explica Pulido Quecedo, "la sentencia clarifica y confirma que las potestades en materia de ejecución presupuestaria anulan cualquier pretensión parlamentaria de admitir enmiendas o proposiciones de ley si el Gobierno se opone, todo ello bajo la invocación del sacrosanto principio de un sistema parlamentario racionalizado" ${ }^{\circ 7}$.

Poco después, la STC 242/2006 de 24 de julio, denegó el amparo solicitado por diputados del G.P. Popular en el Parlamento Vasco contra la decisión de la Mesa de esa Cámara de inadmitir a trámite una proposición de ley por ellos presentada ${ }^{68}$, aceptando de esta forma la disconformidad manifestada por el Gobierno Vasco con la tramitación de dicha proposición por implicar una disminución de los ingresos presupuestarios. La cuestión venía suscitada porque, en un principio, la Mesa sí había admitido a trámite la proposición, pero tras recibir el acuerdo sobre el criterio del Gobierno respecto de la toma en consideración y el relativo al significado presupuestario de la iniciativa, la Mesa de la Cámara adoptó, gracias al voto de calidad del Presidente, un nuevo acuerdo de no admisión a trámite, "de acuerdo con lo dispuesto en el artículo 105 del Reglamento".

Los recurrentes basaban su alegación en que la proposición de ley inadmitida a trámite tenía un ámbito temporal indeterminado que en todo caso no afectaba al ejercicio presupuestario del año 2000, que es en el que se presentó, ni al del año 2001, que es el que, según el Gobierno Vasco, se vería afectado. De este modo, en la medida en que los artículos 105.2 y 103 del

${ }^{66}$ GARCÍA-ESCUDERO MÁRQUEZ, P., "Sobre la calificación...op. cit, p. 55

${ }^{67}$ PULIDO QUECEDO, M., "Sobre cuestiones...op. cit, p. 11.

${ }^{68}$ Proposición de ley sobre modificación del Decreto Legislativo 1/1994, de 27 de septiembre, por el que se aprueba el texto refundido de las disposiciones legales vigentes sobre régimen presupuestario de la Comunidad Autónoma. 
Reglamento del Parlamento Vasco ${ }^{69}$ se refieren al impacto presupuestario en el ejercicio en curso o en vigor, la decisión de inadmisión carecería de cobertura legal, por lo que la Mesa del Parlamento Vasco debería haberse limitado a realizar un control puramente formal de la proposición presentada $\mathrm{y}$, por tanto, haberla admitido a trámite.

En esta ocasión, el TC se separa en alguna medida del razonamiento expuesto en la sentencia anterior ${ }^{70}$, señalando que dicha potestad del Gobierno no es una decisión exenta de control, sino que estaría sometida a unos parámetros tanto temporales como materiales- controlables por la Mesa del Parlamento. En efecto, dice el TC que "resulta evidente que la Mesa del Parlamento Vasco tiene encomendado el control de la disconformidad manifestada por el Gobierno. Sin ir más lejos, y como ya se ha señalado, el art. 105.3 del Reglamento parlamentario otorga al Gobierno un plazo de quince días para ejercer su facultad, transcurrido el cual debe entenderse que la proposición de Ley está en condiciones de ser incluida en el orden del día del Pleno para su toma en consideración. Por otro lado, y como señaló en su día el informe de los Servicios Jurídicos del Parlamente Vasco, dicha disconformidad debe ser expresa y debe basarse en el aumento de los créditos o la disminución de los ingresos presupuestarios como consecuencia de la proposición de Ley objeto de discusión". A su vez, continúa diciendo el Alto Tribunal, "la remisión del art. 105.2 al art. 103 del Reglamento parlamentario también otorga a la Mesa del Parlamento cierto margen de interpretación sobre cuándo puede considerarse que dicho impacto se produce" (FJ 3).

A nuestro juicio, para resolver la contradicción entre las dos sentencias referidas no cabía hacer otra cosa que acudir a la doctrina ya consolidada entre otras, en la propia STC 242/2006 ${ }^{71}$ - del TC según la cual las Mesas de los Parlamentos pueden extender su examen y control de los escritos y documentos parlamentarios más allá de la estricta verificación de los requisitos formales (legitimidad, tiempo, forma) sólo cuando tales escritos y documentos vengan

${ }^{69}$ Actuales arts. 136 y 148.2 RPV.

${ }^{70} \mathrm{~A}$ la que, sorpresivamente, no menciona expresamente. Sobre este particular, Marrero García-Rojo afirma que "La STC 242/2006 llama la atención, ante todo, porque no solo no cita en momento alguno de modo expreso (esto es, identificándola plenamente, de un modo u otro) a la STC 223/2006, sino porque no alude en absoluto a la doctrina de esta para fundar su argumentación. Sin embargo, ello no impide que justo al final de su texto la STC 242/2006 contenga una referencia incidental a un aspecto de la STC 223/2006, que solo se introduce con un inconcreto "como hemos rrecordado recientemente" (lo que, desde luego, contribuye a hacer aún mayor la perplejidad)" ("El control del ejercicio...op. cit., p. 330).

${ }^{71}$ Vid., SSTC 38/1999, de 22 de marzo, FJ 3; 107/2001, de 23 de abril, FJ 3; 203/2001, de 15 de octubre, FJ 3; 177/2002, de 14 de octubre, FJ 3; 40/2003, de 27 de febrero, FJ 2.b; 78/2006, de 13 de marzo, FJ 3.a, entre otras. 
limitados materialmente por la Constitución, el bloque de la constitucionalidad o el Reglamento parlamentario pertinente. Si la legalidad aplicable no impone límite material alguno, la verificación de su admisibilidad ha de ser siempre formal pues, de lo contrario -opina el Alto Tribunal- la Mesa dejaría de obrar como un órgano de gobierno de la Cámara para mutarse en un órgano netamente político.

De este modo, y con el fin de conocer el concreto margen de apreciación de que disponía una Cámara sobre el "veto presupuestario" ejercido por un Gobierno contra una proposición de ley en ella presentada, resultaba imprescindible determinar previamente qué límites materiales encontraba la prerrogativa gubernamental en la Constitución, en los Estatutos de Autonomía y en los Reglamentos parlamentarios. En otras palabras, la Mesa del Parlamento sólo podía apreciar si el Gobierno se había excedido en sus facultades cuando tal capacidad de apreciación/control contaba con previsión normativa expresa (constitucional, estatutaria o incluso reglamentaria).

Pues bien, aunque no de forma literal, de la Constitución deriva un único límite material al ejercicio de la facultad del Gobierno para oponerse a la tramitación de una proposición de ley por motivos presupuestarios: que el aumento de los gastos (créditos) o la disminución de los ingresos que conlleva la proposición de ley afecte al Presupuesto en vigor en el momento de su presentación, y no a la situación futura de la Hacienda una vez expirado ese Presupuesto vigente. Así se deduce del calificativo "presupuestarios" que acompaña en el art.134.6 CE 72 a los "créditos" y a los "ingresos" para indicar que unos y otros han de figurar en el Presupuesto existente ${ }^{73}$. No en vano, como también se ha encargado de remarcar el Tribunal Constitucional en más de una ocasión ${ }^{74}$, la facultad de veto gubernamental se basa en la confianza concedida al Gobierno a través de la aprobación del presupuesto para ejecutar su programa anual de política económica sin que éste sea desnaturalizada a través de iniciativas legislativas parlamentarias, confianza que se conserva a lo largo del período de vigencia natural (o prorrogada) de aquél.

Por su parte, la única norma estatutaria que hace referencia a la prerrogativa del Gobierno analizada, el Estatuto de Autonomía de Extremadura, la somete -esta vez sí de forma expresa- al mismo límite material constitucionalmente reconocido (art. 23.2, redacción tras reforma por Ley Orgánica 1/2011, de 28

72 Así como en los artículos correspondientes del Reglamento del Congreso de los Diputados (art. 126) y de los Reglamentos parlamentarios de Baleares (art. 131.2), Catilla-La Mancha (art. 156.1 y 2), La Rioja (art. 108.1 y 2) y Valencia (art. 125. 2 y 4 d).

${ }^{73}$ Vid., PÉREZ JIMÉNEZ, P.J., "Las limitaciones...op. cit., p. 142.

${ }^{74} \mathrm{Vid}$., SSTC 223/2006, de 6 de julio, FJ 5 y 242/2006, de 24 de julio, FJ 3. 
de enero): la iniciativa legislativa contra la que se ejerza el veto debe suponer minoración de ingresos o aumento de gastos en el ejercicio presupuestario corriente.

Y en cuanto a los Reglamentos parlamentarios, la regulación de la prerrogativa gubernamental en los mismos es diversa:

- El Reglamento del Congreso no añade expresamente ninguna limitación material adicional (art. 126.2 y 3 ).

- El Reglamento del Senado, sin embargo, exige que la no conformidad del Gobierno sea motivada (art. 151.3).

- Los Reglamentos parlamentarios de Madrid (art. 151.1 y 2), Castilla y León (art. 122.2 y 3) y Galicia (art. 123.2) incluyen como limitación que los efectos presupuestarios de la proposición de ley vetada afecten al presupuesto en vigor.

- Los Reglamentos parlamentarios de Canarias (art. 135.4), Murcia (art. 119.1) y País Vasco (art. 148.2) requieren que la oposición del Ejecutivo sea motivada.

- Los Reglamentos parlamentarios de Andalucía (art. 124.3 y 4), Asturias (art. 153.2), Aragón (art. 139.1), Extremadura (art. 160.3), Navarra (art. 148.3) y Cataluña (art. 111.2) exigen tanto que el veto sea motivado o fundado como que el aumento de los créditos o disminución de los ingresos anejos a la proposición vetada se produzcan en el ejercicio económico en curso.

- Y el resto de Reglamentos parlamentarios (Castilla-La Mancha, Baleares, La Rioja, Cantabria y Comunidad Valenciana) no contienen limitación alguna, regulando la capacidad de veto del Gobierno de manera similar a la Constitución y al Reglamento del Congreso.

A la vista, pues, del examen de la legalidad expuesto, todas las Cámaras legislativas españolas (Congreso de los Diputados, Senado y Parlamentos autonómicos) pueden rechazar un veto presupuestario del Gobierno cuando el impacto financiero de la proposición de ley vetada se produzca en distinto ejercicio presupuestario a aquel en que tal proposición se presenta, ya que tal limitación material de la facultad gubernamental tiene carácter general al traer su origen directo del art. 134.6 de la Constitución. Pero sólo aquellas Cámaras cuyos Reglamentos exigen expresamente que el Gobierno motive 
suficientemente su veto (en concreto, el Senado y las Asambleas legislativas de Canarias, Murcia, País Vasco, Andalucía, Asturias, Aragón, Extremadura, Navarra y Cataluña) tienen abierto un control material más amplio del mismo desde la perspectiva de la proporcionalidad y la razonabilidad.

Sin embargo, recientemente el Tribunal Constitucional ha resuelto la cuestión de manera distinta, al entender atribuida entre las competencias de calificación de iniciativas de la Mesa del Parlamento la de apreciar si el Gobierno se ha excedido en su prerrogativa, con independencia de si existe o no previsión normativa específica. A analizar con más detenimiento la nueva doctrina del TC dedicamos el siguiente apartado.

4.1.2. La visión restrictiva de la potestad de veto en la reciente doctrina del Alto Tribunal

En efecto, el TC se ha encargado dedeterminar el alcance de la potestad de veto del Gobierno -y, por lo tanto, también de la capacidad de control sobre el mismo que ostenta la Cámara- en la STC 34/2018, de 12 de abril, que desestima el conflicto planteado por el Gobierno contra el Congreso de los Diputados en relación con el veto presupuestario opuesto por aquél a la tramitación de una proposición de ley del PSOE de suspensión del calendario de implantación de la llamada "Ley Wert" (Ley Orgánica 8/2013, de 9 de diciembre, para la Mejora de la Calidad Educativa).

Esta sentencia precisa cuáles son los límites de la prerrogativa gubernamental:

1) sólo puede afectar a iniciativas legislativas que "incidan directamente sobre el Presupuesto aprobado", esto es, sobre "los gastos e ingresos del sector público estatal" (art. 134.2 CE), porque "suponga aumento de los créditos o disminución de los ingresos presupuestarios" (arts. 134.6 CE);

2) esa incidencia presupuestaria debe ser "real y efectiva" (no meramente estimativa o hipotética) y, además, debe referirse al presupuesto en vigor, no a presupuestos futuros;

3) el Gobierno, que dispone de un amplio margen de apreciación en su estimación de si la iniciativa legislativa en cuestión afecta, y en qué medida, a los ingresos y gastos del presupuesto, cuando decida oponer su veto debe hacerlo de manera motivada (arts. 126.2 y 3 del Reglamento del Congreso de los Diputados), "precisando adecuadamente los concretos créditos que se verían directamente afectados, de entre los contenidos en el presupuesto en vigor" (FJ 7) ${ }^{75}$.

${ }^{75}$ Vid., DUQUE VILLANUEVA, J. C., ORTEGA CARBALLO, C., LOSADA GONZÁLEZ, H. y DE LA QUADRA-SALCEDO JANINI, T., "Doctrina del Tribunal Constitucional durante 
Por su parte, la Mesa del Congreso no está vinculada automáticamente por el veto del Gobierno, ya que la Mesa está facultada para pronunciarse "sobre el carácter manifiestamente infundado del criterio del Gobierno, siempre y cuando resulte evidente, a la luz de la propia motivación aportada por este, que no se ha justificado la afectación de la iniciativa a los ingresos y gastos contenidos en el propio presupuesto que, en cada ejercicio, cumple la función instrumental a la propia acción de Gobierno". Esta función de la Mesa "tiene en todo caso carácter jurídico-técnico, no respondiendo en ningún caso a criterios de oportunidad política". En suma, la Mesa, sin sustituir la apreciación del Gobierno, puede rechazar el veto cuando compruebe que el Gobierno no ha justificado que la iniciativa legislativa que pretende vetar afecta de forma real y efectiva a los presupuestos en vigor, en forma de disminución de los ingresos o de aumento de los créditos presupuestarios (FJ 7).

En cuanto al control constitucional posible en este tipo de conflictos, se advierte que el TC no puede sustituir ni la apreciación del Gobierno acerca de la afectación al presupuesto, ni tampoco la calificación de la medida que lleva a cabo la Mesa de la Cámara; tan solo le corresponde determinar si el rechazo al veto del Gobierno ha producido el menoscabo de la competencia que a este le otorga el art. 134.6 CE, para lo cual resulta necesario examinar tanto la motivación exteriorizada por el Gobierno al invocar la potestad del art. 134.6 CE como la expresada por la resolución de la Mesa del Congreso que rechaza el veto (FJ 8).

Proyectada esta doctrina al concreto supuesto enjuiciado, el TC concluye que el rechazo por la Mesa del Congreso al veto presupuestario del Gobierno a la tramitación de la proposición de ley referida a la suspensión del calendario de implantación de la LOMCE no ha menoscabado la competencia que al Gobierno le atribuye el art. 134.6 CE. Es así porque éste no explicitó de qué manera habrían resultado afectados los presupuestos en vigor, sino que se limitó a plantear un escenario hipotético, que dependía de las decisiones que las instituciones europeas pudieran adoptar en el futuro, todo ello en referencia a la posible pérdida de aportaciones del Fondo Social Europeo relacionadas con programas ligados a la implantación de la Ley Orgánica para la Mejora de la Calidad Educativa. Por consiguiente, la apreciación de la Mesa de la Cámara, al considerar que la motivación del Gobierno resulta insuficiente para verificar la "efectiva conexión" de la iniciativa legislativa con los ingresos y los gastos públicos del presupuesto en vigor, no supuso en este caso el menoscabo de la competencia del poder ejecutivo (FJ 9).

el primer cuatrimestre de 2018", en Revista Española de Derecho Constitucional, 113, 2018, pp. 229-276. 
La doctrina sentada en la STC 34/2018 se reitera en la STC 44/2018, de 26 de abril, que resuelve el segundo de los conflictos de atribuciones entre el Gobierno y la Mesa del Congreso, el planteado por el Gobierno ante el rechazo de su veto presupuestario en relación con una proposición de ley, también presentada por el PSOE, sobre modificación del art. 42.1 del Estatuto de los Trabajadores, para garantizar la igualdad en las condiciones laborales de los trabajadores subcontratados.

El TC desestima también en este caso el conflicto planteado por el Gobierno contra la Mesa del Congreso, que rechazó el veto presupuestario a la tramitación parlamentaria de la iniciativa legislativa por entender que el Gobierno no justificó de manera objetiva y suficiente que la misma implique aumento de créditos o disminución de ingresos de los presupuestos en vigor, por considerar que el rechazo por la Mesa de la Cámara al veto tampoco ha menoscabado la competencia que al Gobierno le atribuye el art. 134.6 CE, pues la motivación del Gobierno para justificar su criterio no cumple la exigencia de precisar adecuadamente las concretas partidas presupuestarias del presupuesto en vigor que se verían directamente afectadas por esa iniciativa legislativa, al haberse limitado a aportar una estimación de impacto económico, insuficiente a estos efectos.

En fin, el TC ha advertido nuevamente al Ejecutivo sobre el uso extralimitado que ha hecho de su prerrogativa de veto a iniciativas de la oposición en tres recursos de amparo: SSTC 94/2018, de 17 de septiembre ${ }^{76} ; 139 / 2018$, de 17 de diciembre ${ }^{77}$; y 17/2019, de 11 de febrero $^{78}$. En dichas sentencias el TC

${ }^{76}$ Recurso de amparo promovido por el G.P. Unidos Podemos-En Comú Podem-En Marea del Congreso de los Diputados contra el acuerdo de la Mesa del Congreso de los Diputados de 28 de abril de 2017, que, con aceptación del criterio del Gobierno de la Nación, había resuelto la no procedencia de someter la proposición de ley para el cierre de las centrales nucleares instaladas en España que dicho grupo parlamentario había presentado para su toma en consideración por el Pleno del Congreso de los Diputados, así como contra el acuerdo de la misma Mesa de 6 de junio de 2017, que desestimó la solicitud de reconsideración formulada contra el mismo.

${ }^{77}$ Recurso de amparo promovido por el G.P. Socialista del Congreso de los Diputados contra el acuerdo de la Mesa del Congreso de los Diputados de 24 de octubre de 2017 que, con aceptación del criterio del Gobierno de la Nación, resolvió la no procedencia de someter la proposición de ley sobre modificación de la regulación de la unidad de convivencia en determinadas situaciones, a efectos del acceso y mantenimiento en el percibo de las pensiones de la Seguridad Social en su modalidad no contributiva, que dicho grupo parlamentario había presentado, para su toma en consideración por el Pleno del Congreso de los Diputados, así como contra el acuerdo de la misma Mesa de 21 de noviembre de 2017, que desestimó la solicitud de reconsideración formulada contra el anterior.

${ }^{78}$ Recurso de amparo promovido por el G.P. Unidos Podemos-En Comú Podem-En Marea del Congreso de los Diputados contra el acuerdo de la mesa del Congreso de los Diputados de 10 de octubre de 2017 que, con aceptación del criterio del Gobierno de la Nación, resolvió que no procedía someter a la toma de consideración la proposición de ley, de modificación del Real 
reitera lo que afirmó en abril de 2018 al resolver los conflictos de atribuciones, reafirmando la necesidad de interpretar restrictivamente esta potestad en manos del Ejecutivo, y declara inconstitucionales los Acuerdos de la Mesa del Congreso que admitieron dichos vetos, por entender que el Ejecutivo se ha extralimitado en el uso de dicha potestad, vulnerando el derecho al ejercicio del cargo público parlamentario de los proponentes de la iniciativa (art.23.2 CE) y el derecho de los ciudadanos a participar en los asuntos públicos a través de representantes (art. 23.1 CE). La consecuencia de ello es la retroacción de actuaciones para que la Mesa dicte unos Acuerdos que cumplan con las exigencias constitucionales del veto y que, por consiguiente, admita a trámite las proposiciones de ley para que puedan ser tomadas en consideración.

\section{2. ¿De qué vías dispone el Gobierno -estatal y autonómico-para activar el control del acuerdo por el que Cámara rechaza su veto?}

Por lo que se refiere a las posibilidades de que dispone el Gobierno para reaccionar contra el acuerdo parlamentario que rechaza su veto, cabe distinguir dos clases de control:

a) El control interno o interparlamentario. Esta clase de control está vedado, en principio, al Gobierno -tanto el estatal como los autonómicos-, pues éste no puede hacer uso del medio impugnatorio previsto en los Reglamentos parlamentarios para articular la fiscalización parlamentaria de los acuerdos de calificación y admisión a trámite, al que suele denominarse "solicitud de reconsideración", ya que esta vía interna se encuentra reservada al parlamentario o grupo parlamentario autor de la iniciativa ${ }^{79}$.

Decreto Legislativo $2 / 2015$, de 23 de octubre, por el que se aprueba el texto refundido de la Ley del estatuto de los trabajadores, al objeto de fortalecer la negociación colectiva en la regulación de las relaciones laborales, que el referido grupo parlamentario había presentado para su toma en consideración por el pleno del Congreso de los Diputados; así como contra el acuerdo de la misma mesa, de fecha 21 de noviembre de 2017, que desestimó la solicitud de reconsideración formulada contra el mismo.

79 Por otra parte, si la Mesa (o la Junta de Portavoces en Navarra o la Comisión de Economía y Presupuestos en Aragón) acepta la disconformidad presupuestaria del Gobierno y pone fin a la tramitación de una proposición de ley, los parlamentarios o grupos autores de la misma pueden pedir la reconsideración del acuerdo y, si su solicitud no es atendida, pueden recurrir el mismo en amparo si, conforme a lo dispuesto en el art. 42 LOTC, viola los derechos y libertades susceptibles de amparo constitucional y dentro del plazo de tres meses desde que, con arreglo a las normas internas de la Cámara, aquel acuerdo sea firme, es decir, desde que se adopta el acuerdo de reconsideración. El resto de sujetos titulares de la iniciativa legislativa a través de proposiciones de ley carecen, sin embargo, de legitimación para utilizar esta vía parlamentaria interna, ausencia de legitimación que, en el caso concreto de las proposiciones de ley remitidas a la Mesa del Congreso por una Asamblea autonómica, no casa 
Sin embargo, cinco de esos Reglamentos sí incluyen previsiones para los casos en que exista una discrepancia entre el Gobierno y la Cámara acerca de la incidencia o no de una proposición en los cálculos presupuestarios:

- En la Cámara Alta tal discrepancia será resuelta por el Presidente de la Cámara (art. 151.5 del Reglamento del Senado) ${ }^{80}$.

- En el Parlamento de Andalucía decidirá el Pleno, tras un debate en el que intervendrán los distintos Grupos parlamentarios en un único turno de diez minutos (art. 124.4 del Reglamento del Parlamento de Andalucía).

- En la Junta General del Principado de Asturias decidirá también el Pleno en la primera sesión que celebre, a propuesta de la Mesa, oída la Junta de Portavoces (art. 153.5 del Reglamento de la Junta General del Principado de Asturias).

- En el Parlamento de Navarraserá la Junta de Portavoces la que decida sobre la tramitación de la proposición de ley (art. 148.3 del Reglamento del Parlamento de Navarra).

- Y en la Asamblea de Madrid resolverá en última instancia la Mesa, pero a diferencia de los supuestos anteriores, sólo si el Gobierno plantea su discrepancia (art. 151.4 del Reglamento de la Asamblea de Madrid).

b) Por lo que se refiere a la viabilidad de un segundo tipo de control al que podemos llamar, por contraste del órgano que lo ejerce, externo o jurisdiccional, varía según se trate de una proposición de ley estatal o autonómica:

- Contra el acuerdo adoptado por la Mesa del Congreso o el Pleno del Senado $^{81}$, el Gobierno de la Nación puede plantear un conflicto de

\footnotetext{
con la lógica de un sistema que permite que la defensa de este tipo de proposiciones en el trámite de toma en consideración ante el Pleno del Congreso se lleve a cabo por delegados nombrados por las Asambleas proponentes, de modo que lo coherente habría sido que el Reglamento del Congreso de los Diputados permitiera a esos mismos delegados la utilización de la vía prevista en el art. 31.2 RC.

${ }^{80}$ Nada prevé, sin embargo, el Reglamento del Congreso en estos casos. Para GARCÍA MARTÍNEZ, M.A. [El procedimiento legislativo, Congreso de los Diputados, 1987, pp. 243244], podría aplicarse, aun sin estar recogido en el Reglamento, el mismo criterio que en el Senado, por analogía o en aplicación de las facultades que el art. $32.2 \mathrm{RC}$ confiere al Presidente del Congreso. VIVER PI-SUNYER, C., ["Proposición de ley", en M. Aragón Reyes (coord.), Temas Básicos de Derecho Constitucional, t. II (Organización del Estado), Civitas, 2001, pp. 173-174)] señala que, a pesar de que no se prevea ninguna instancia arbitral, no parece descabellado pensar que la última palabra la tendrá el Pleno de la Cámara.
} 
atribuciones ante el Tribunal Constitucional ${ }^{82}$. Y si la proposición de ley vetada fuera finalmente aprobada por las Cortes, también podría interponer contra esta ley (a través del Presidente del Gobierno) un recurso de inconstitucionalidad por inobservancia en el procedimiento legislativo del art. $134.6 \mathrm{CE}^{83}$.

- Pero cuando el acuerdo es adoptado por una Parlamento regional, el Gobierno autonómico respectivo carece de legitimación tanto para plantear un conflicto de atribuciones ${ }^{84}$, como para interponer, en el caso de que la proposición vetada se convierta en ley autonómica, un recurso de inconstitucionalidad contra ésta ${ }^{85}$, lo que sin duda coloca a los Ejecutivos

${ }^{81} \mathrm{Al}$ resolver, acabamos de verlo, la discrepancia Gobierno-Mesa a favor de ésta.

${ }^{82}$ De acuerdo con lo dispuesto en el art. 73 LOTC, con carácter previo al planteamiento del conflicto el Gobierno deberá solicitar de la Cámara la revocación de su decisión (dentro del mes siguiente a la fecha en que ésta llegue a su conocimiento). Si el rechazo de su veto se produce en el Congreso, tal requerimiento de revocación se dirigirá, pues, a la Mesa de esta Cámara; pero si tiene lugar en el Senado, el requerimiento irá dirigido al Presidente de la Cámara Alta, pues a él corresponde, en todo caso, la resolución de las controversias sobre la calificación de las proposiciones de ley y enmiendas, y la de los incidentes que puedan surgir en relación con esta cuestión (art. 151.5 RS). Por otra parte, PUNSET BLANCO, R. [en "La fase central...op. cit., nota (2 bis), pp. 114-115], en relación con la calificación de las enmiendas financieras, después de señalar que "el Gobierno puede plantear, ex art. 73 de la LOTC, un conflicto de competencia contra la decisión parlamentaria no ofrece dudas", añade que "incluso cabe opinar (aunque no lo disponga la LOTC) que el TC está obligado a declarar la suspensión del procedimiento legislativo hasta que recaiga sentencia $\{\ldots\}$...

${ }^{83}$ De hecho, el Gobierno barajó esa posibilidad en relación con la proposición del G.P. Socialista para la defensa de la LOMCE, citada en el texto, si ésta acaba siendo aprobada. Sobre la posibilidad de declarar inconstitucional una ley por vicios en el procedimiento legislativo Vid., entre otros, PÉREZ JIMÉNEZ, P.J., "Las limitaciones...op. cit., p. 158; BIGLINO CAMPOS, P., "Vicios en el procedimiento legislativo", en M. Aragón Reyes (coord.), Temas Básicos de Derecho Constitucional, t. II (Organización del Estado), Civitas, 2001, pp. 163-165, y ARANDA ÁLVAREZ, E., Los actos parlamentarios...op. cit., pp. 249-255. Dicha posibilidad, además, aparece claramente admitida por el Tribunal Constitucional: vid., STC 76/1983, donde declara que "el sistema constitucional de distribución de competencias entre los distintos órganos constitucionales limita también las posibilidades de las Cortes Generales en el ejercicio de la función legislativa", y STC 124/1995, entre otras.

${ }^{84}$ En virtud del art. 73.1 c) LOTC, el Tribunal Constitucional entenderá sólo de los conflictos que opongan al Gobierno con el Congreso de los Diputados, el Senado o el Consejo General del Poder Judicial; o a cualquiera de estos órganos constitucionales entre sí.

${ }^{85}$ De acuerdo con el art. 32.2 LOTC, los órganos colegiados ejecutivos de las Comunidades Autónomas carecen de legitimación para recurrir en vía directa contra las leyes, las disposiciones o los actos con fuerza de Ley de su propia Comunidad Autónoma. Y así lo vino a confirmar el Tribunal Constitucional, entre otras, en la STC 223/2006 citada en el texto, que inadmite por esta causa -falta de legitimación del recurrente- el recurso de inconstitucionalidad interpuesto por el Consejo de Gobierno de la Junta de Extremadura contra los arts. 111.1 (párrafo segundo) y 121.4 (párrafo segundo) del Reglamento de la Asamblea de Extremadura. Contra esta decisión el Magistrado don Vicente Conde Martín de Hijas formuló Voto particular (al que se adhirieron los Magistrados don Javier Delgado Barrio y don Roberto García-Calvo y Montiel) cuyo criterio 
autonómicos en una poco entendible posición de indefensión frente a la decisión de la Cámara.

\section{CONCLUSIONES}

La fraccionada composición que, con carácter general, presentan los Parlamentos españoles (Cortes Generales y Asambleas de las Comunidades Autónomas) como resultado de las diferentes elecciones autonómicas y generales celebradas a partir del año 2015, marcada por el descenso de los dos grandes partidos mayoritarios y la irrupción de nuevas formaciones políticas, determinantes ahora de la gobernabilidad, ha afectado profundamente a las pautas prácticas de todas las funciones parlamentarias, y muy particularmente, de la potestad legislativa, hasta el punto de poder afirmar, sin temor a equivocarnos, que el enfrentamiento entre el Gobierno y el Parlamento se ha convertido en la regla general del quehacer legislativo.

Por un lado, los Gobiernos ahora en minoría encuentran graves obstáculos para sacar adelante muchas de sus iniciativas legislativas -tanto sus proyectos de ley como las que impulsa a través de su grupo parlamentario-, especialmente las de carácter presupuestario, a la vez que las proposiciones de ley presentadas por la oposición no sólo crecen exponencialmente, sino que, por primera vez desde la restauración de la democracia en 1978, rebasan en porcentaje de éxito a las iniciativas del Gobierno. Por otro lado, esos mismos Ejecutivos, en contra de lo que venía siendo costumbre en anteriores legislaturas, no han dudado en ejercer con profusión su prerrogativa para oponerse a la tramitación de proposiciones de ley presentadas por la oposición (y, en el caso del Congreso de los Diputados, también de las remitidas por las Asambleas Legislativas de Comunidades Autónomas) que suponen aumento de los gastos o disminución de ingresos presupuestarios.

En la práctica parlamentaria española lo normal ha sido que los sucesivos Gobiernos hayan evitado la utilización de esta última posibilidad, conocida como veto presupuestario, sobre todo por su muy mala imagen política y

compartimos. Según el mismo, se debía de haber reconocido la legitimación del Consejo de Gobierno de la Junta de Extremadura porque la misma se funda directamente en el art. 162.1 a) CE, que reconoce en términos de rotunda claridad, y sin ninguna clase de restricciones, condicionamientos ni remisiones a la LOTC la legitimación "para interponer el recurso de inconstitucionalidad", entre otros, a "los órganos colegiados ejecutivos de las Comunidades Autónomas". En consecuencia, no se puede compartir la tesis mayoritaria expresada en la Sentencia que hace prevalecer la literalidad de lo dispuesto en el art. 32 LOTC sobre lo dispuesto en términos inequívocos en el referido precepto de la Constitución. 
porque resulta más cómodo actuar a través de su mayoría parlamentaria, que se limita a rechazar las proposiciones de ley provenientes de la oposición en el trámite de la toma en consideración. Sin embargo, durante la XII Legislatura de las Cortes Generales el Gobierno de Mariano Rajoy ha batido todos los registros, habiendo paralizado hasta el triunfo de la moción censura de Pedro Sánchez la tramitación de más de 40 iniciativas de la oposición y de las Comunidades Autónomas -10 de ellas, por cierto, estando en funciones-; aumento de vetos que, aunque en menor medida, también se ha producido en las legislaturas autonómicas.

Lo que quiso el constituyente al atribuir al Gobierno la prerrogativa de veto presupuestario es evitar que el Parlamento, a través de la aprobación de diferentes leyes o de enmiendas a las mismas, desvirtúe los Presupuestos previamente aprobados por las propias Cámaras. Así se salvaguarda, en último término, la función de gobierno, que podría verse obstaculizada si los Presupuestos, que son la base para desarrollar el programa político de cualquier Ejecutivo, se ven alterados por la actividad parlamentaria. Ahora bien, dado que el veto presupuestario limita de forma muy notable la actividad legislativa de las Cámaras y el derecho fundamental de participación política, su uso debe estar rodeado de garantías. Así pues, cuando su fin no es salvaguardar la acción política del Gobierno en materia presupuestaria, sino paralizar de manera indiscriminada las proposiciones de ley de la oposición ante la falta de una mayoría sólida que le permita hacerlo en un estadio más avanzado del procedimiento legislativo, deja de ser presupuestario para convertirse, simplemente, en un auténtico veto gubernamental no conciliable con nuestro sistema constitucional de atribuciones.

Y así se lo ha advertido recientemente el Tribunal Constitucional al Ejecutivo tras una primera doctrina sobre el veto un tanto equívoca- en 2 conflictos entre órganos constitucionales (SSTC 34/2018 y 44/2018) y en 3 recursos de amparo (SSTC 94/2018, 139/2018 y 17/2019). En estas sentencias el Tribunal recalca, en primer lugar, que el veto presupuestario sólo puede oponerse a aquellas proposiciones de ley que supongan un aumento de los gastos o una disminución de los ingresos del ejercicio presupuestario en curso, de manera que no cabe interponerlo sobre la base de consecuencias económicas futuras. En segundo lugar, el TC subraya que la incidencia de la proposición de ley en el presupuesto debe ser directa e inmediata, de forma que el Gobierno tiene que explicar qué partidas presupuestarias y de qué forma resultan comprometidas por la iniciativa en cuestión. Y, en tercer lugar, el TC exige que el acuerdo de la Mesa por el que decide aceptar el veto presupuestario interpuesto por el Gobierno esté motivado, de manera que no puede limitarse a señalar que el Gobierno ha ofrecido una fundamentación suficiente y razonable sobre el 
uso del veto, sin responder a los distintos argumentos esgrimidos por los grupos parlamentarios proponentes acerca de que la falta de afectación presupuestaria, pues ello supone ofrecer una justificación abstracta y formalista que no cumple con la función de control que aquélla tiene atribuida.

Estos pronunciamientos del Tribunal Constitucional han de servir como clara advertencia a los distintos Ejecutivos acerca de lo que puede y no puede hacerse en ejercicio de la facultad de veto. Se trata, al fin y al cabo, de que el veto presupuestario funcione como una prerrogativa al servicio del Presupuesto, y no como un privilegio al servicio del Gobierno y de su mayoría parlamentaria, al que recurrir cuando no existan demasiadas garantías de que la proposición de ley sea rechazada por la Cámara o cuando siquiera resulte conveniente o cómodo discutir acerca de su rechazo.

¿Y qué puede hacer, en fin, el Gobierno -ya sea el de la Nación o uno de Comunidad Autónoma- cuando la Mesa rechaza su veto?

Ningún Ejecutivo, ya sea el central o uno autonómico, podrá, en principio, solicitar de la Cámara la reconsideración del acuerdo parlamentario que rechaza su veto, si bien los Reglamentos del Senado y de cuatro Asambleas autonómicas (Andalucía, Asturias, Madrid y Navarra) sí incluyen previsiones para los casos en que exista una discrepancia entre el Gobierno y la Cámara acerca de la repercusión o no de la proposición de ley vetada en los cálculos presupuestarios.

Lo que sí podrá hacer el Gobierno de la Nación -y sólo el Gobierno de la Nación- es plantear un conflicto de atribuciones ante el Tribunal Constitucional; y si la proposición de ley vetada llegara a ser aprobada, interponer contra la misma un recurso de inconstitucionalidad por inobservancia en el procedimiento legislativo previsto en el art. 134.6 CE. Posibilidades todas ellas vedadas a cualquier Gobierno autonómico, lo que coloca a los Ejecutivos regionales en una poco justificable situación de indefensión frente al eventual rechazo de sus vetos por parte de las Asambleas de las Comunidades Autónomas.

\section{BIBLIOGRAFÍA CITADA}

- AJA FERNÁNDEZ, E., "Caracteres y principios generales del procedimiento legislativo", en $A D P, 1983$.

- ARAGÓN REYES.M., "La organización institucional de las Comunidades Autónomas", en REDC, núm. 79, 2007. 
- ARAGÓN REYES, M., Uso y abuso del Decreto-ley: una propuesta de reinterpretación constitucional, Iustel, 2016.

- ARANDA ÁLVAREZ, E.: Los actos parlamentarios no normativos y su control jurisdiccional, CEPC, 1998.

- ARCE JANÁRIZ, A., "Calificación y admisión a trámite en los procedimientos parlamentarios”, en REDC, núm. 29, 1990.

- ARCE JANÁRIZ, A., "El trámite de admisión de los procedimientos parlamentarios en la Jurisprudencia Constitucional”, en $R E D C$, núm. 46, 1996.

- BIGLINO CAMPOS, P., "Vicios en el procedimiento legislativo", en M. Aragón Reyes (coord.), Temas Básicos de Derecho Constitucional, tomo II, Civitas, 2001.

- BILBAO UBILLOS, J.M.: "Un nuevo ciclo político sin mayorías absolutas: los Parlamentos autonómicos recobran protagonismo tras las elecciones de 2015”, en RJCL, núm. 42, 2017.

- DUQUE VILlANUEVA, J. C.; ORTEGA CARBALlO, C.; LOSADA GONZÁLEZ, H., y DE LA QUADRA-SALCEDO JANINI, T., "Doctrina del Tribunal Constitucional durante el primer cuatrimestre de 2018", en REDC, núm. 113, 2018.

- GARCÍA ESCUDERO-MÁRQUEZ, P., "Un nuevo parlamento fragmentado para los 40 años de la Constitución”, en RDP, núm. 101, 2018.

- GARCÍA ESCUDERO-MÁRQUEZ, P., La iniciativa legislativa del Gobierno, CEPC, 2000.

- GARCÍA ESCUDERO-MÁRQUEZ, P., El procedimiento legislativo ordinario en las Cortes Generales, CEPC, 2006.

- GARCÍA ESCUDERO-MÁRQUEZ, P., "Sobre la calificación de las Enmiendas de contenido presupuestario (A propósito de la STC 223/2006, de 6 de junio)", en RATC, núm. 13, 2006.

- GARCÍA ESCUDERO-MÁRQUEZ, P., "Gobierno en funciones y función legislativa", en $C M G A$, núm. 11, 2016. 
- GARCÍA MAJADO, P., "Del uso al abuso del veto presupuestario" (19/ 04/2018). Agenda Pública El País. Recuperado de: www.agendapublica. elpais.com.

- GARCÍA MARTÍNEZ, M.A., El procedimiento legislativo, Congreso de los Diputados, 1987.

- GARCÍA MORILLO, J. y PÉREZ TREMPS, P., "Legislativo vs. Ejecutivo autonómicos: El problema del control del "veto presupuestario", en Parlamento y Constitución: ADP Castilla-La Mancha, núm. 2, 1998.

- GIMÉNEZ SÁNCHEZ, I.M., "El veto presupuestario del gobierno: ¿mecanismo de bloqueo parlamentario?” (26/10/2018). Agenda Pública El País. Recuperado de: www.agendapublica.elpais.com.

- GIMÉNEZ SÁNCHEZ, I.M., Las competencias presupuestarias del Parlamento, CEPC, 2008.

- GIMÉNEZ SÁNCHEZ, I.M., "El control del Parlamento sobre el llamado "veto presupuestario" del Gobierno", en RJCL, núm.42, 2017.

- MARRERO GARCÍA-ROJO, A., "El control del ejercicio por el Gobierno de la facultad de veto presupuestario (Comentario a la STC 223/2006, con consideración de la STC 242/2006)", en REDC, núm. 80, 2007.

- MARTÍN REBOLLO, L., "Uso y abuso del Decreto-ley. Un análisis empírico", en REDA, núm. 174, 2015.

- MARTÍNEZ LAGO, M.A.: Los límites a la iniciativa de las Cortes Generales en materia presupuestaria, Ministerio de Economía y Hacienda, 1990.

- MERINO MERCHÁN, J.F., "Las facultades de calificación de las enmiendas por las Mesas de las Cámaras", en RCG, núm. 23, 1991.

- MERINO MERCHÁN, J.F., "Elementos para un estudio de los actos del procedimiento legislativo", en Los actos del Parlamento, Parlamento Vasco, 1999.

- ORTEGA SANTIAGO, C., "Actualización de los instrumentos de control del parlamento (O de cómo el control parlamentario se adapta a los tiempos y a las circunstancias)", en SEIJAS VILLADANGOS, E. (coord.), Parlamento y parlamentarismo: origen y retos. Tirant Lo Blanch, Valencia, 2018. 
- PARRA GÓMEZ. D., "La función legislativa en Parlamentos fragmentados", en Seijas Villadangos, E. (coord.), Parlamento y parlamentarismo: origen y retos. Tirant Lo Blanch, Valencia, 2018.

- PEÑA RODRÍGUEZ, L., "Calificación y admisión a trámite de iniciativas legislativas", en V Jornadas de Derecho Parlamentario, El procedimiento legislativo, 1998.

- PÉREZ JIMÉNEZ, P.J., "Las limitaciones a la iniciativa legislativa financiera en la Constitución española", en $R D P$, núm. 9, 1981.

- PULIDO QUECEDEO, M., "Sobre cuestiones presupuestarias de índole parlamentaria", en RATC, núm. 13, 2006.

- PUNSET BLANCO, R., "La fase central del procedimiento legislativo", en REDC, núm. 14, 1985.

- SANZ PÉREZ, A.L., “Existe doble confianza en nuestro parlamentarismo? Comentario a la STC 242/2006”, en RATC, núm. 3, 2007.

- VISEDO MAJÓN, F.J., y SORIANO HERNÁNDEZ, E., Las enmiendas en el procedimiento legislativo. Asociación Española de Letrados de Parlamentos, 2000.

- VIVER PI-SUNYER, C., “Proposición de ley”, en M. Aragón Reyes (coord.), Temas Básicos de Derecho Constitucional, tomo II, Civitas, 2001.

\section{Artículos de prensa online sin autor:}

- El Gobierno de Rajoy es el que ha vetado más leyes de la oposición (24/04/2017). europapress. Recuperado de: www.europapress.com.

- El PSOE mantendrá activado un plan B para derogar la Lomce (09/01/2017). La Rioja.com. Recuperado de: www.larioja.com.

- Los letrados del Congreso defienden el veto del Gobierno a leyes si no es «arbitrario» (13/12/2016). ABC. Recuperado de: www.abc.es.

- Congreso y Gobierno, más cerca de su segundo conflicto de atribuciones ante el TC. (13/12/2016). ABC. Recuperado de: www.abc.es. 
- La oposición se une para reclamar que se elimine el 'impuesto al sol' (25/01/2017). El País. Recuperado de: www.elpais.com.

- Ciudadanos se une al PP para mantener el 'impuesto al sol' (14/03/2017). infoLibre. Recuperado de: www.infolibre.es.

- El Gobierno de Sánchez acepta tramitar en el Congreso 18 proposiciones de ley de la oposición que vetó Rajoy (15/06/2018). EcoDiario. Recuperado de: www.ecodiario.eleconomista.es. 